\title{
Effects of Seismic Waves in Water Level Changes in a Well: Empirical Data and Models
}

\author{
G. N. Kopylova ${ }^{a, *}$ and S. V. Boldina ${ }^{a, * *}$ \\ ${ }^{a}$ Kamchatka Branch, Federal Research Center "Geophysical Survey of the Russian Academy of Sciences”, \\ Petropavlovsk-Kamchatskii, 683006 Russia \\ *e-mail: gala@emsd.ru \\ **e-mail: boldina@emsd.ru
}

Received March 13, 2019; revised July 8, 2019; accepted October 7, 2019

\begin{abstract}
The high-precision water level measurements with a sampling interval of 5-10 min were carried out in 1996-2017 in the YuZ-5 well, Kamchatka. In the obtained time series, water level variations caused by the passage of seismic waves (hydrogeoseismic variations-HGSV) during 19 earthquakes with $M_{w}=6.8-9.1$ which occurred at epicentral distances of $80-14.6$ thousand $\mathrm{km}$ are revealed. Based on the HGSV morphological features, four main types of these variations are distinguished: oscillations (I); short (up to tens of hours) water level rises (II) superimposed on oscillations; short rises (III); and long (1.5-3 months) drawdowns (IV). The dependence of the occurrence of the revealed GHSV types on earthquake parameters (magnitude and distance), specific energy density and maximum seismic wave velocity, and the amplitude-frequency content of ground motion is analyzed based on the records at a nearest seismic station. Based on several case studies, hydrogeodynamic processes of HGSV formation are investigated using numerical modeling. It is shown that the forced and free amplitude fluctuations in the water level (types I and II) can arise due to the enhancement of groundwater pressure variations in the well-water-bearing rock system during the passage of surface seismic waves with periods corresponding to the resonant frequency of the well $(\tau=44.6 \mathrm{~s})$. The rise in the water level in well lasting for tens minutes to hours (types II and III of HGSV variation) is caused by the short increase in pressure under violation of the steady water flow in the direct vicinity of the well; strong local earthquakes accompanied by ground shaking with intensity $I_{\text {msk-64 }} \geq 5$ cause sustained drawdowns (type IV) due to pressure drop with the amplitudes up to 0.1 bar within a radius of up to a few hundred meters from the well.
\end{abstract}

Keywords: hydrogeoseismic variations, amplitude-frequency content of ground motion

DOI: $10.1134 /$ S1069351320030039

\section{INTRODUCTION}

Propagation of seismic waves during earthquakes is accompanied by various disturbances in the hydrodynamic regime of the ground and surface waters: by the changes in their discharge, pressure and water levels (Wang and Manga, 2010). During the strongest earthquakes with magnitudes of the order of 9 such the Alaska 1964, Sumatra-Andaman 2004; Tohoku, Japan, 2011 events, the effects of seismic waves were recorded at distances up to tens of thousands $\mathrm{km}$ from the epicenter, reflecting the planetary-scale influence of such earthquakes on the hydrodynamic regime of the Earth's hydrosphere.

Observations of water level fluctuations in the piezometer wells are traditionally employed in the systems of geophysical monitoring and searching for earthquake precursors in the seismically active regions (Kissin, 1993; Kopylova, 2006). In these studies, it is required to estimate the properties of the observation wells as "sensors" of the changes in the stress-strain state of the geological medium during the seismotectonic processes, barometric, tidal, and other natural and technogenic impacts (Kopylova, 2009). Besides, the recording of different effects of seismic waves in the changes of water level in wells provides new empirical data for solving topical scientific problems associated with the study of vibration action on the state of a fluid-saturated medium in the seismically active regions and the hydrogeodynamic processes in the well-water-bearing rock system.

The effects of vibration action of seismic waves which manifest themselves in the changes of the water level are hereinafter referred to as water level hydrogeoseismic variations or HGSV. Different HGSV types reflect the integrated changes in the groundwater pressure under the dynamic deformation of water-bearing rocks and the concomitant filtration processes caused by the changes in the properties of the water-bearing rocks, mainly their permeability (Kopylova and Boldina, 2007; Wang and Manga, 2010). As the mecha- 
nisms of the change in permeability, different authors proposed the development of fracture dilatancy in water-bearing rocks (Bower and Heaton, 1978; Kanamori and Brodski, 2004; Kopylova and Boldina, 2007), groundwater degassing (Roeloffs, 1998; Kopylova et al., 2012), unclogging of the fracture-pore space (Brodsky et al., 2003; Kocharyan et al., 2011), effects of cumulative accumulation of interblock deformations (Kocharyan et al., 2007).

The HGSV have been extensively described in the literature, e.g., in a generalizing paper (Wang and Manga, 2010). Recently, most HGSV data have been obtained in China where an observational network incorporating more than six hundred wells is organized (Sun and Liu, 2012; Shi et al., 2015; Sun et al., 2015). On Taiwan, during the the Chi-Chi earthquake of 1999 with $M_{w}=7.5$, observations were conducted on a network of several hundred wells (Wang et al., 2001; Chia et al., 2008). Water level variations in individual wells were monitored in the USA (Woodcook and Roeloffs, 1996; Roeloffs, 1998), in Japan (Matsumoto and Roeloffs, 2003), in the Caucasus (Georgia) (Chelidze et al., 2019), in Russia on the East European platform (Kocharyan et al., 2011), in the Kamchatka Peninsula (Kopylova et al., 2016; 2017; Kopylova and Boldina, 2019), and in other seismically active regions (Kopylova et al., 2007). Studying the specificity of HGSV manifestations in individual wells makes it possible to investigate hydrogeodynamic processes initiated in the well-water-bearing rock system by seismic waves and to track the changes in the state of the water-saturated medium with time. Solving these problems is a necessary condition for efficient geophysical monitoring of seismically active and aseismic territories using methods of near-surface geophysics (Adushkin and Spivak, 2014).

The HGSV data recorded with a sampling frequency corresponding to that of ground surface displacement recordings by seismic instruments (a few to tens $\mathrm{Hz}$ ) is of particular scientific interest. In these cases, separate seismic phases can be reliably distinguished in water level variations, providing new possibilities for studying hydrogeodynamic processes in a well-water-bearing rock system in the high-frequency region (Shalev et al., 2016ab; Besedina et al., 2016).

However, most of the HGSV records were obtained with a sampling interval of water level from 1 to $10-15 \mathrm{~min}$ (Roeloffs, 1998; The Monitoring ..., 2007; Kopylova et al., 2017; Chelidze et al., 2019). Such HGSV records are informative with respect to the coseismic components of a static change in the stress state of waterbearing rocks at epicentral distances $d_{e}$ on the order of 2-3 lengths $D$ of an earthquake source (Wakita, 1975; Kopylova, 2006; Kopylova et al., 2010). The HGSV occurrences in these cases characteristically have complex character with the coseismic jumps in the water level recorded directly during the passage of seismic waves and then are changed by various postseis- mic (postdynamic according to (Kocharyan et al., 2011)) water level variations. In the far zones of earthquake sources $\left(d_{e} / D \gg 3 D\right)$, water level variations are dominated by oscillations (Cooper et al., 1965; Kopylova and Boldina, 2007; etc.).

The examples of systematization of HGSV data in terms of their form, duration, and time of occurrence relative to the time of rupture formation in the source and the time of arrivals of seismic waves in the region of the observation wells are presented in (Kopylova, 2006; Shi et al., 2015; Boldin, 2017). The division of HGSVs into the coseismic effects observed during the action of seismic waves and the post-seismic effects developing some time after the termination of seismic shaking is the one most substantiated by the empirical data.

Among the coseismic HGSVs, Shi et al. (2015) distinguish three main types:

- the jump-like water level drawdowns or rises (abrupt or step-like changes) at epicentral distances $d_{e}$ up to a few hundred $\mathrm{km}$ as a groundwater pressure response to the static component of coseismic deformation of water-bearing rocks during the strong earthquakes (Wakita, 1975; Kopylova et al., 2010; 2012; Shi et al., 2013; 2015);

-water level oscillations due to the dynamic deformation of water-bearing rocks and harmonic variations in pressure upon the arrival of body and surface seismic waves (Cooper et al., 1965; Kopylova and Boldina, 2007; Kopylova et al., 2012; Shi et al., 2015).

- gradual water level increase or decrease (gradual change, see (Shi et al., 2015)) or a "post-dynamic response" (Kocharyan et al., 2011) reflecting pressure variations caused by the change in the permeable properties of water-bearing rocks; examples of various manifestations are presented in (Kopylova, 2001; Brodsky et al., 2003; Roeloffs et al., 2003; Kopylova et al., 2012; 2016).

The studies using high-frequency digital instruments revealed complex forms of the coseismic HGSVs with the superposition of jumps and oscillations (Weingarten, Ge, 2014), as well as superposition of oscillations and gradual changes in the water level in wells (Wang et al., 2001). This shows that simplified schemes of the types of coseismic HGSVs are not quite applicable for describing the HGSVs in the individual observation wells, and this issue requires further elaboration based on high-quality data of high-frequency recording of groundwater level (pressure).

Shi et al., (2015) analyzed the observational data from the wells in mainland China during the strongest earthquakes of 2007-2011 with $M_{w}=7.9-9.0$ in the regions of Sumatra, Japan, and China to show that the coseismic HGSV at the epicentral distances $d_{e} / D>1$ are dominated by water level oscillations (observed in $\sim 40 \%$ of the wells). At the shorter epicentral distances $\left(d_{e} / D<1\right)$, water level jumps are the prevailing GHSV type which is observed in $\sim 39 \%$ of the wells. The pre- 
sented statistical estimates appear to be not fully convincing because the study relies on the data from the wells where water level was sampled on an hourly basis. Besides, the examples of coseismic water level variations are presented on a time interval of one day, on which it is impossible to assess the correlation between the revealed water level variations and seismic wave arrivals. As shown in (Kopylova et al., 2010), in order to reliably diagnose coseismic jumps and other short-term effects in the changes of the water level, the latter should be recorded at a rate of at least once per $10-15$ minutes. The measurements with a larger sampling interval are almost inapplicable for detecting the coseismic jumps as they are strongly contaminated by the noise produced by seismic waves, baric, tidal, and other natural and technogenic processes.

In (Shi et al., 2015) it is also noted that any changes in the water level were not recorded in $22-43 \%$ of wells. In our opinion, the probable causes of the absence of GHSV could, inter alia, include technical imperfection of the observation methods at individual wells and insufficient degree of detail in the analysis of water level variations compared to the arrivals of seismic waves.

Among the postseismic water-level variations, Shi et al. (2015) distinguish two their types: the long-term, or sustained changes - the co-seismic changes lasting from several weeks to several months, and short-term, transient changes - the co-seismic changes lasting less than one week. This division of the postseismic HGSVs seems to be quite adequately substantiated by the empirical data except for their strict limitation by the cited time boundaries which may vary for the individual wells depending on the construction of the latter and on the filtration properties of water-bearing rocks. The examples of sustained post-seismic water level changes in wells are presented in (Roeloffs, 1998; Kopylova, 2001; Boldina and Kopylova, 2017; Zhang et al., 2018); the short-term post-seismic changes in water level are described in (Kopylova et al., 2016; 2017; Boldina and Kopylova, 2017).

We also note that HGSV manifestations differ in the wells penetrating the loose sedimentary rocks with pore type permeability and in the wells drilled in the consolidated hard rock formations with predominantly fracture-type permeability. The diversity of the water level responses in the closely located wells penetrating dispersed incoherent rocks at the depths of tens to hundreds $\mathrm{m}$ is explained by the varying degree of compaction/decompaction of these rocks and the effects of partial or total liquefaction during dynamic deformation (Wang and Manga, 2010). In these wells, dramatic HGSV manifestations with amplitudes of water level oscillations up to tens of meters, with pouring out of water and ejection of rock fragments (Chia et al., 2008). In the HGSV manifestations in such wells, the main role is played by the local structural features of the stratum of water-bearing rocks and the threshold values of its dynamic strain. Typically, these wells control groundwater of the first aquifer from the surface and, due to the strong deformability of the water-bearing rocks and the contamination of the water level records by the noise factors, have a limited use in the geophysical monitoring systems. The wells penetrating the consolidated weakly fractured water bearing rocks are more promising objects for geophysical monitoring of seismically active territories. The water changes in these wells record baric and Earth's tidal responses, the response to static coseismic deformation under rupture formation in the sources of the local earthquakes (Kopylova, 2009; Kopylova et al., 2012), as well as hydrogeodynamic precursors at the stages of preparation of the strong earthquakes (Kopylova and Boldina, 2019).

In this paper, we present the HGSV data recorded in the changes of water level in a 800-m deep well YuZ-5, Kamchatka, using digital instruments. The observations have been conducted since 1997 for studying hydrogeodynamic precursors of earthquakes and other seismic effects in the changes of water levels (Kopylova, 2006; Kopylova et al., 2012; 2016; 2017; Kopylova and Boldina, 2019). In the YuZ-5 well, HGSV were detected during 19 earthquakes of 19972017 with $M_{w}=6.8-9.1$ at epicentral distances $d_{e}=$ 80-14600 km (Fig. 1, Table 1.). Based on these data, we present the updated typification of the HGSV; consider the dependence of the occurrences of individual HGSV types on the parameters of the earthquakes and peculiarities of the amplitude-frequency content of the maximal phases of ground motion recorded at the Petropavlovsk seismic station (PET) located at a distance of $\sim 20 \mathrm{~km}$ from the well. In several examples, using modeling, we analyze the processes of formation of the selected HGSV types in the well-water-bearing rock system.

\section{INITIAL DATA AND STUDY METHOD}

The Kamchatka Branch of the Federal Research Center "Unified Geophysical Survey of the Russian Academy of Sciences" (KB FRC UGS RAS) conducts long-term observations of water level variations in the YuZ-5 well with the use of instrumental systems Kedr A2 (1997-2004, sampling interval $10 \mathrm{~min}$ ) and Kedr DM (2005-2017, sampling interval 5 min) equipped with a highly sensitive ultrasonic water level sensor. The instruments are manufactured by OOO Polinom, Khabarovsk. The water level measurement instruments are described in (Kopylova and Boldina et al., 2016; 2017). During the entire observation period, the sensitivity of water level measurements was $0.1 \mathrm{~cm}$ and of atmospheric pressure measurements, $0.1 \mathrm{hPa}$.

The data on the YuZ-5 well are presented in (Kopylova, 2006; Kopylova et al., 2016; 2017; Boldina and Kopylova, 2017). The well is located at $53.169^{\circ} \mathrm{N}$, $158.414^{\circ} \mathrm{E}$ and has a depth of $800 \mathrm{~m}$. In the depth interval $0-310 \mathrm{~m}$, the wellbore is cased with a metal 


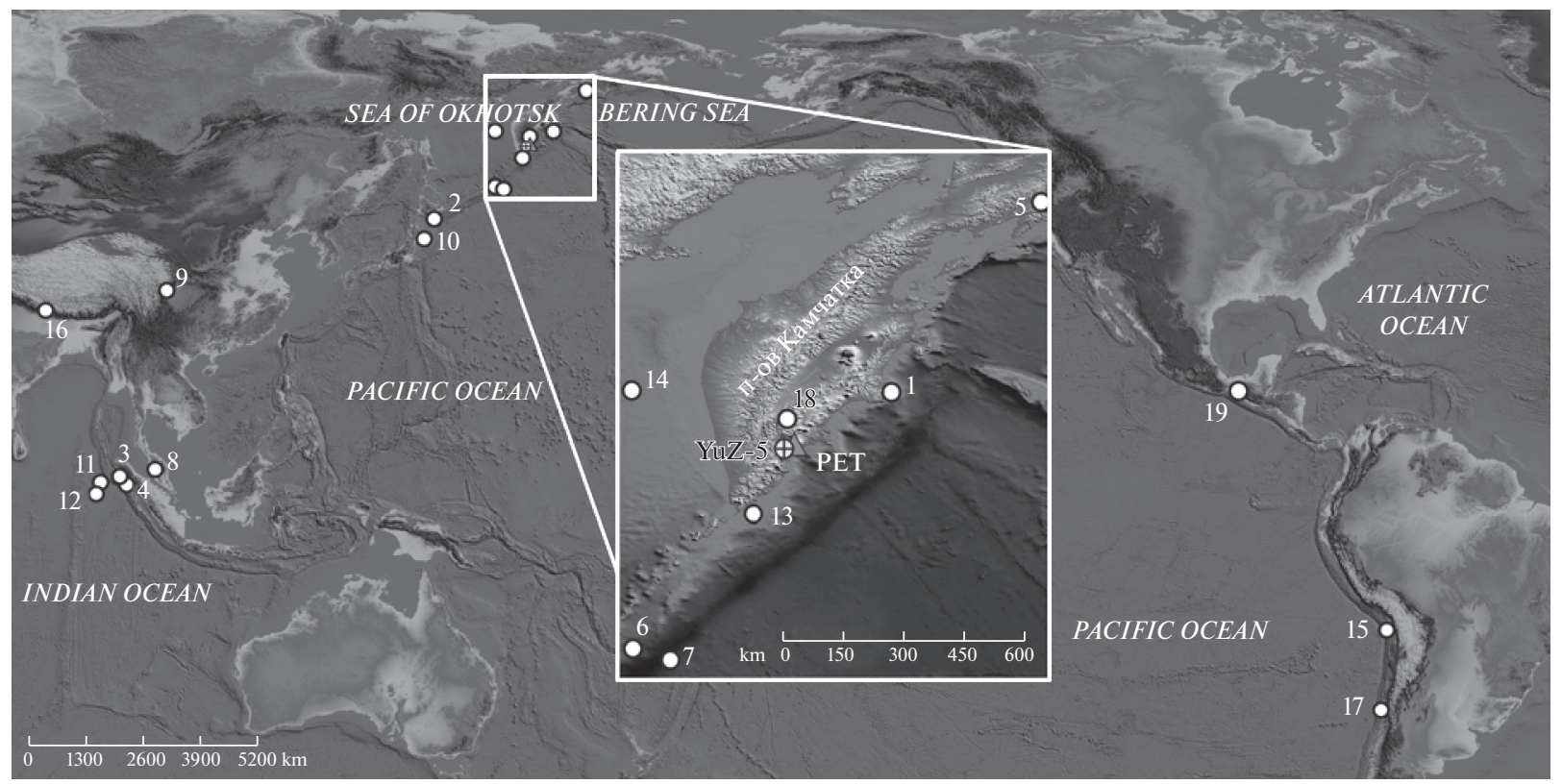

Fig. 1. Schematic layout of earthquake epicenters (Table 1), YuZ-5 well and Petropavlovsk seismic station (PET) (inset).

pipe. At the depths of $310-800 \mathrm{~m}$, the wellbore is open and connected with water-bearing rocks represented by siltstones and Late Cretaceous schists. Their transmissivity $T=7.8 \mathrm{~m}^{2} /$ day was estimated from pumping data (Kopylova and Boldina, 2007). Groundwater mineralization is $0.25 \mathrm{~g} / 1$. The water table is at a depth of $1-1.5 \mathrm{~m}$ below the ground surface.

The background water level changes contain intraannual seasonal variations with amplitude of up to $50 \mathrm{~cm}$, barometric, and tidal variations (Kopylova, 2006; 2009; Boldina and Kopylova, 2017). According to the results of cross-spectral analysis of hourly records of the water level and atmospheric pressure, the barometric efficiency of water level variations in the period range from $6 \mathrm{~h}$ to a few tens of days is $0.4 \mathrm{~cm} / \mathrm{hPa}$; at periods from 2 to $6 \mathrm{~h}$, the barometric efficiency monotonically increases from 0.1 to $0.4 \mathrm{~cm} / \mathrm{hPa}$. The sensitivity of water level variations to volumetric strain of water-bearing rocks in the diurnal and semidiurnal groups of tidal waves is $0.161 \mathrm{~cm} / 10^{-9}$. The data on the structure of the well, elastic and filtration properties of water-bearing rocks, regularities of the hydrogeodynamic regime, and the description of the HGSV at strong local and remote earthquakes are presented in the previous publications (Kopylova, 2006; 2009; Kopylova and Boldina, 2006; Kopylova et al., 2010 Boldina and Kopylova, 2013; 2016; 2017; Boldina, 2017) and on the KB FRC UGS RAS website http://www.emsd.ru/lgi/places/uz5.

Among the set of the recoded HGSVs (Fig. 1, Table 1), four types are identified according to morphological features (the shape) and duration (Table 1, Fig. 2 Fig. 5) (Kopylova et al., 2017):

-type I: forced and free oscillations lasting for a few hours to one day (Fig. 2);

IZVESTIYA, PHYSICS OF THE SOLID EARTH Vol. 56 -type II: oscillations with superimposed shortterm, from minutes and hours to days, residual rises (Fig. 3);

-type III: short-term residual rises lasting for hours to one day (Fig. 4);

-type IV: sustained (1.5-3 months) water level drawdowns (Fig. 5).

HGSV in Figs. 2-5 are compared with the records of seismic waves at the Petropavlovsk seismic station (s/st PET, $53.024^{\circ} \mathrm{N}, 158.653^{\circ} \mathrm{E}$ ) by STS-1 sensor in the BHZ channel with sampling frequency of $20 \mathrm{~Hz}$.

The accepted rate of water level sampling once per 5-10 min allows reliable identification of HGSV of types III and IV and evaluation of their parametersamplitudes and durations. At the same time, this sampling rate does not provide reliable estimates of the amplitudes and durations of HGSV of types I and II which reflect forced fluctuations of water level immediately during the arrival of seismic waves and free decaying oscillations after the passage of seismic waves. From on the 10- and 5-min records of type I and II HGSV, it is only possible to establish the very fact of the presence of these variations which is recognized by the increase in the amplitude of water level changes and the presence of characteristic "peaks" (Figs. 2 and 3). Therefore, when characterizing the HGSV of types I and II (Table 1), we present the values of the maximum recorded amplitudes (with the sign " $\geq$ ") which are most likely to be less than their real values.

In September 2017, in addition to the Kedr DM, a PAA 36XW Keller sensor (Switzerland) and a CR-6 Cambell data logger (USA) recorder were installed at 


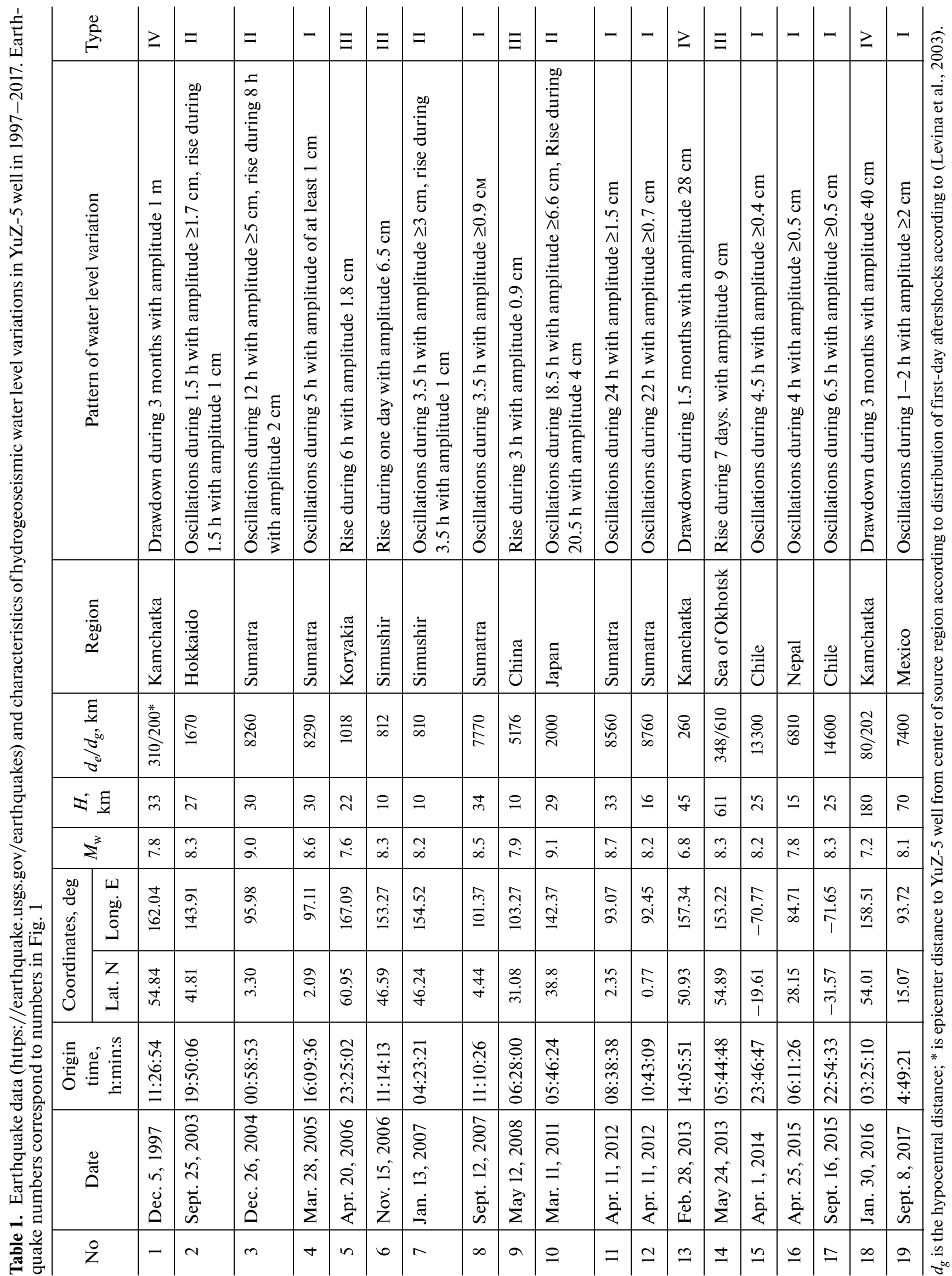


No. 4

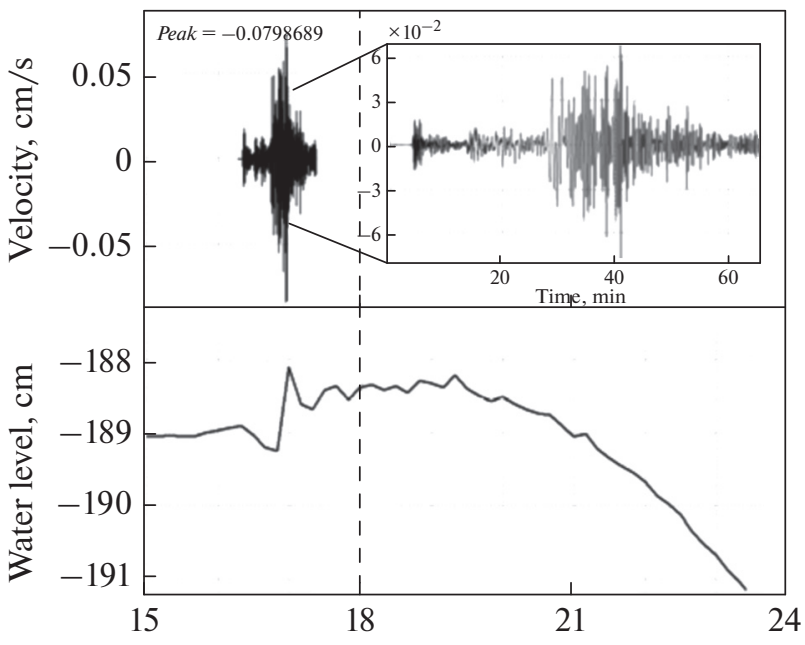

$\times 10^{-2}$

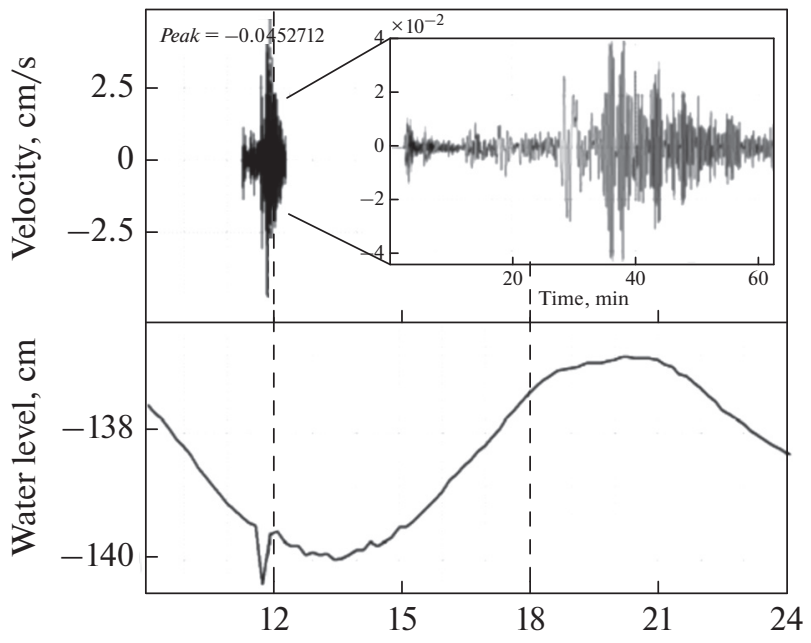

Nos. 11,12

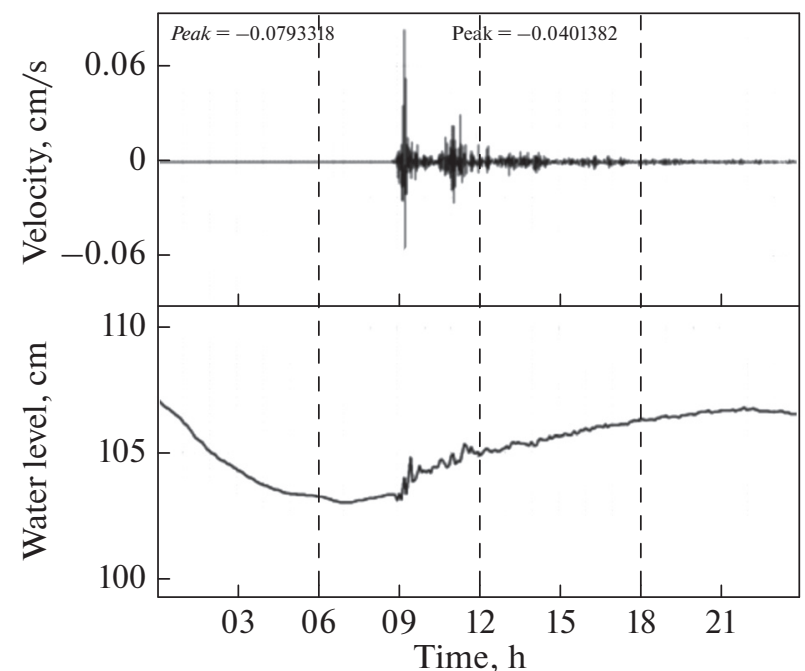

Type I

No. 15

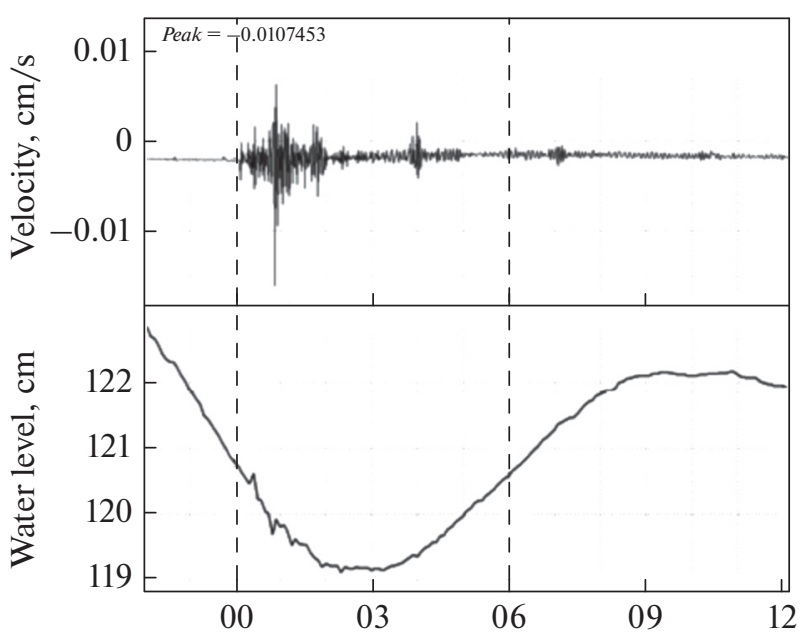

No. 16
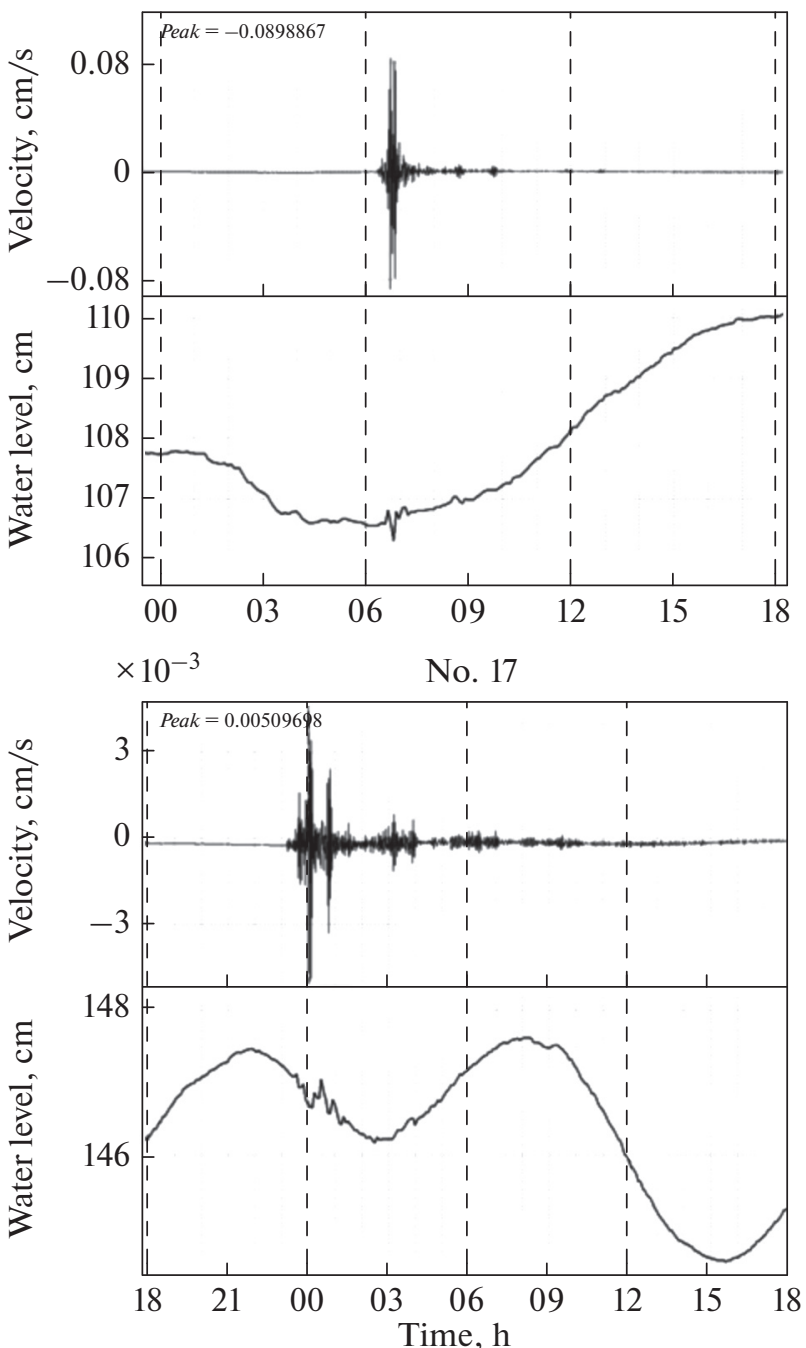

Fig. 2. Type I hydrogeoseismic variations of water level in YuZ-5 well compared with e earthquake records in BHZ channel, PET. Earthquake numbers correspond to Table 1 and Fig. 1. 


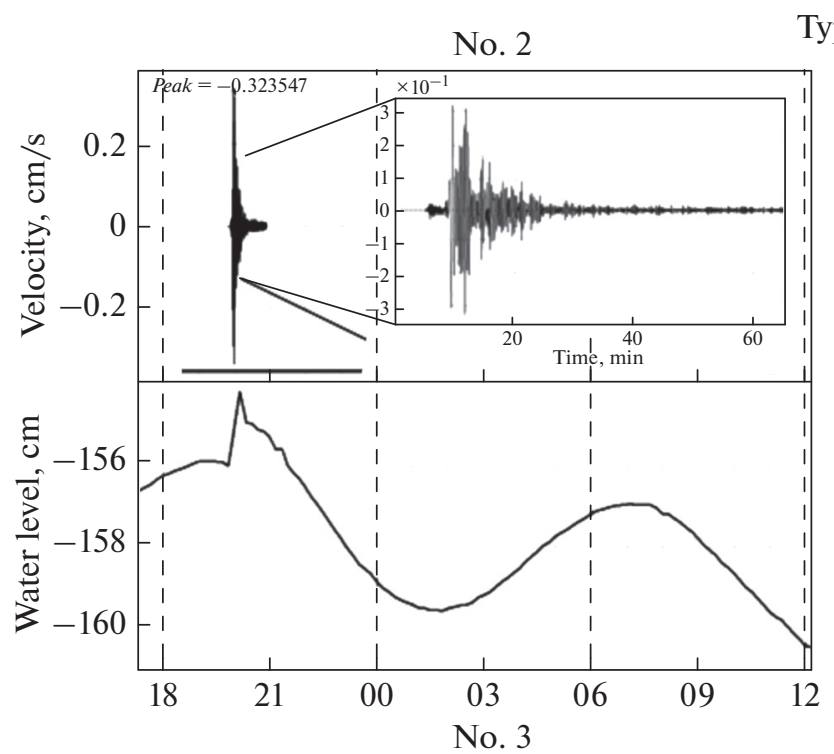

Type II
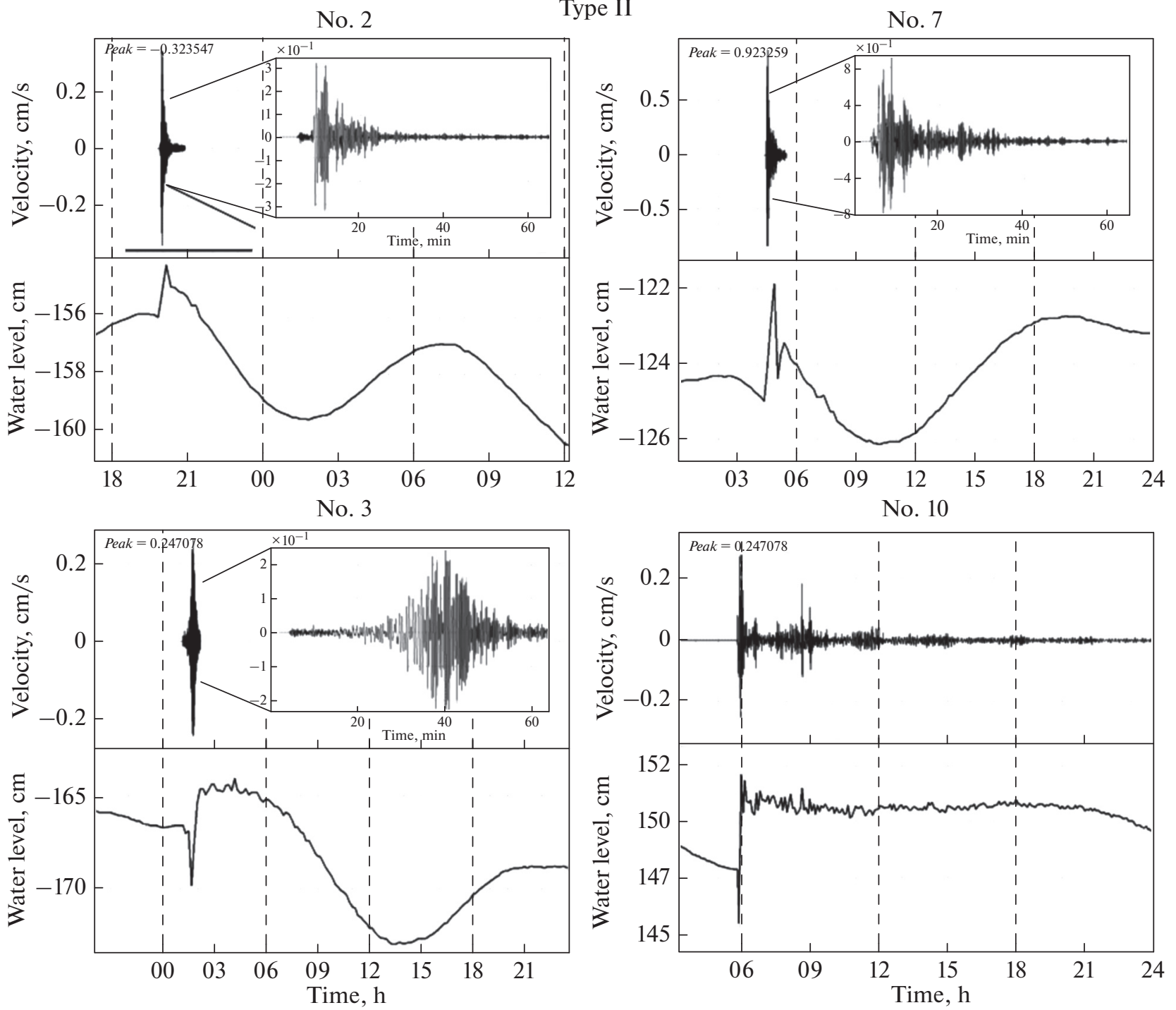

Fig. 3. Type II hydrogeoseismic variations of water level in YuZ-5 well compared with e earthquake records in BHZ channel, PET. Earthquake numbers correspond to Table 1 and Fig. 1.

the well for recording pressure variations at a depth of $5.6 \mathrm{~m}$ with sampling frequency of $10 \mathrm{~Hz}$. The comparison of the data for September-December 2017 obtained by the two sets of instruments demonstrate their identity in determining the pattern of seasonal trend and the parameters of barometric and tidal responses of water level in well.

On September 9, 2017, an earthquake $M_{w}=8.2$ occurred in the region of Mexico (no. 19 in Table 1 and in Fig. 1). This earthquake was accompanied by the changes in the water level (pressure) recorded by both sets of instruments. Figure 6 shows the 5-min water level data recorded by Kedr DM during the passage of seismic waves from this earthquake together with $10-\mathrm{Hz}$ records of pressure and ground surface displacements in BHZ channel of PET seismic station.
In the $10-\mathrm{Hz}$ records of groundwater pressure, the distinct arrivals of $S$ - and $L$-waves are seen, identical to the seismic record. The duration of pressure oscillations was at least $1.5 \mathrm{~h}$ with a maximum amplitude of $3 \mathrm{hPa}$ which is equivalent to $3 \mathrm{~cm}$ of water column. The 5-min measurements of the water level also indicate the presence of type I HGSV with a duration of at least one hour with a maximum recorded amplitude of water level oscillations of $2 \mathrm{~cm}$, which is a factor of 1.5 less than the recorded variations in groundwater pressure.

The presented example demonstrates the possibility of recognizing types I and II of HGSV based on the 5-min water level data and obtaining the approximate estimates of the amplitudes, duration, and character of these variations (Table 1). 
Type III
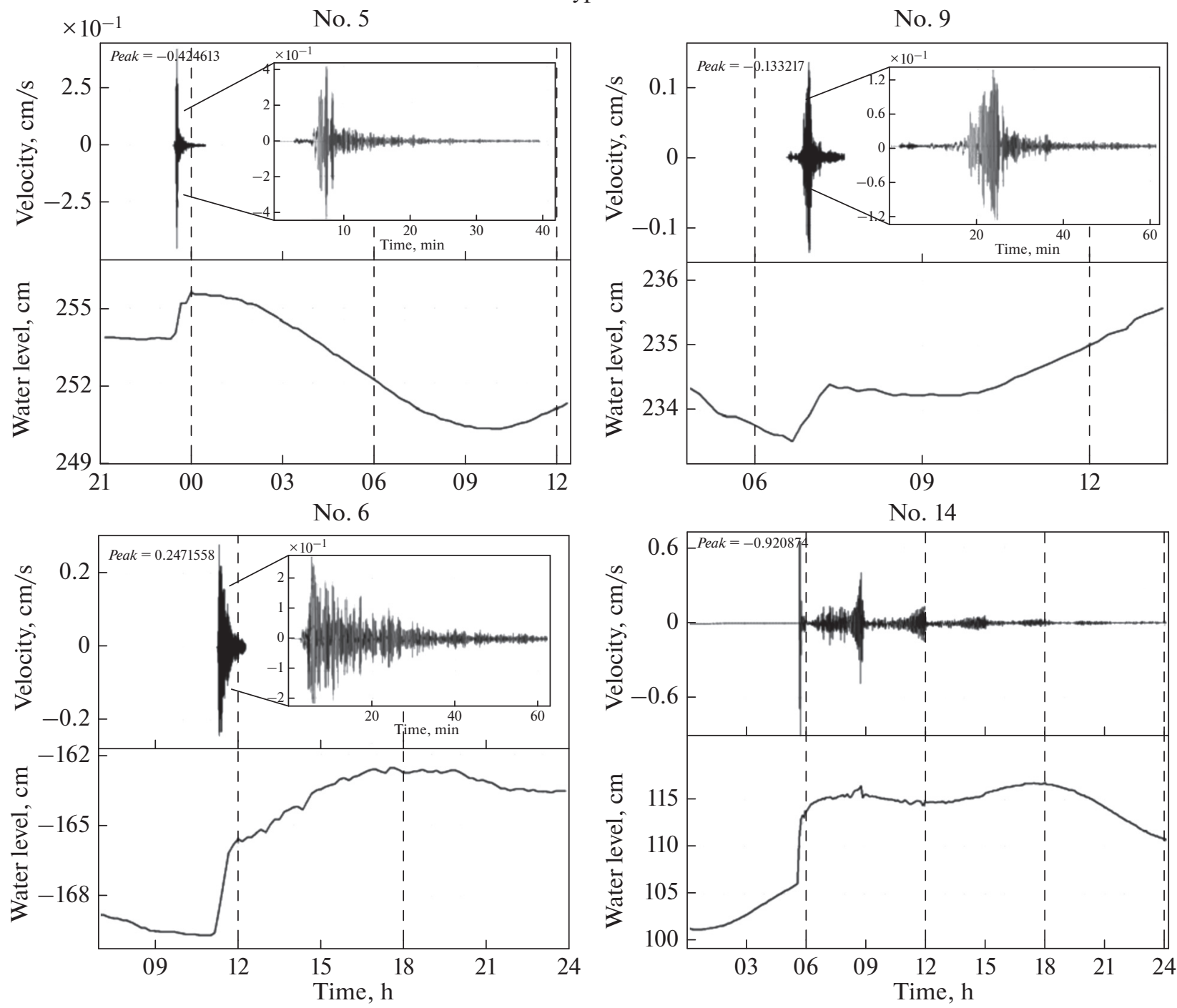

Fig. 4. Type III hydrogeoseismic variations of water level in YuZ-5 well compared with earthquake records in BHZ channel, PET. Earthquake numbers correspond to Table 1 and Fig. 1.

\section{ESTIMATING THE INTENSITY \\ OF THE EFFECT OF SEISMIC WAVES IN THE VICINITY OF A WELL}

For estimating the seismic impact on the natural fluid dynamic systems, Wang and Manga (2010) used the parameter of specific energy density in a seismic wave $e, \mathrm{~J} / \mathrm{m}^{3}$ :

$$
\log d_{e}=0.48 M_{w}-0.33 \log e-1.4,
$$

where $d_{e}$ is epicentral distance in $\mathrm{km}$ and $M_{w}$ is the magnitude of the earthquake. In Table 2, we present the values of $e$ in the region of the YuZ-5 well calculated by formula (1).

As the intensity parameter of seismic impact, we also considered the peak ground velocity $V_{m}$ in $\mathrm{cm} / \mathrm{s}$ in a well zone during the earthquakes (Table 1). This parameter was estimated based on the dependences presented in (Gomberg et al., 2006):

$$
\begin{gathered}
V_{m}=81 /\left(0.9+d_{e} / D\right)^{2}, \\
V_{m}=21 /\left(d_{e} / D\right)^{1.5},
\end{gathered}
$$

where $D$ is the maximum linear size of earthquake source in $\mathrm{km}$ calculated by the formula of (Riznichenko, 1976):

$$
\log D=0.44 M_{w}-1.289 \text {. }
$$

The average $V_{m}$ values calculated by formulas (2), (3) are presented in Table 2.

Figure 7 shows the distribution of the four HGSV types as function of the ratio between $M_{w}, d_{e}$ and $e$ (Fig. 7a) and $M_{w}, d_{e}$ and $V_{m}$ (Fig. 7b). The obtained 


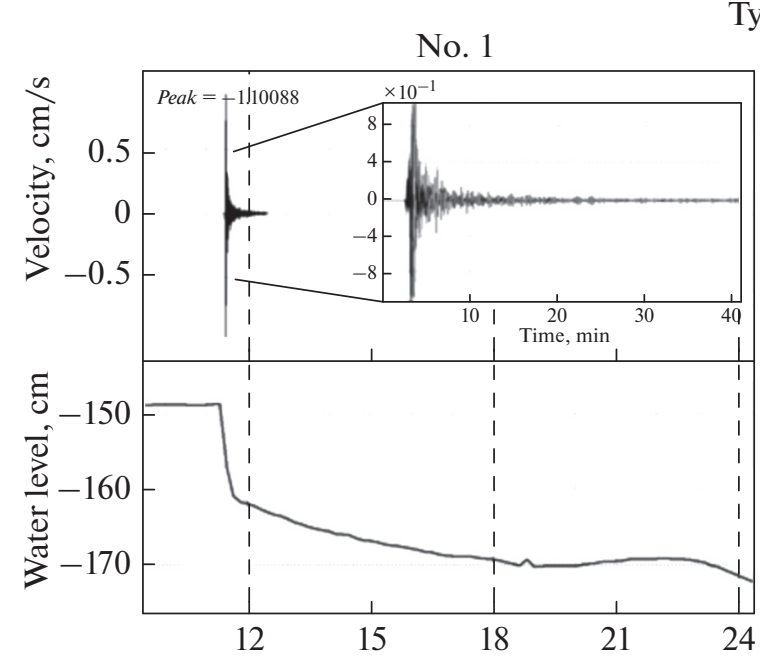

Type IV

No. 13
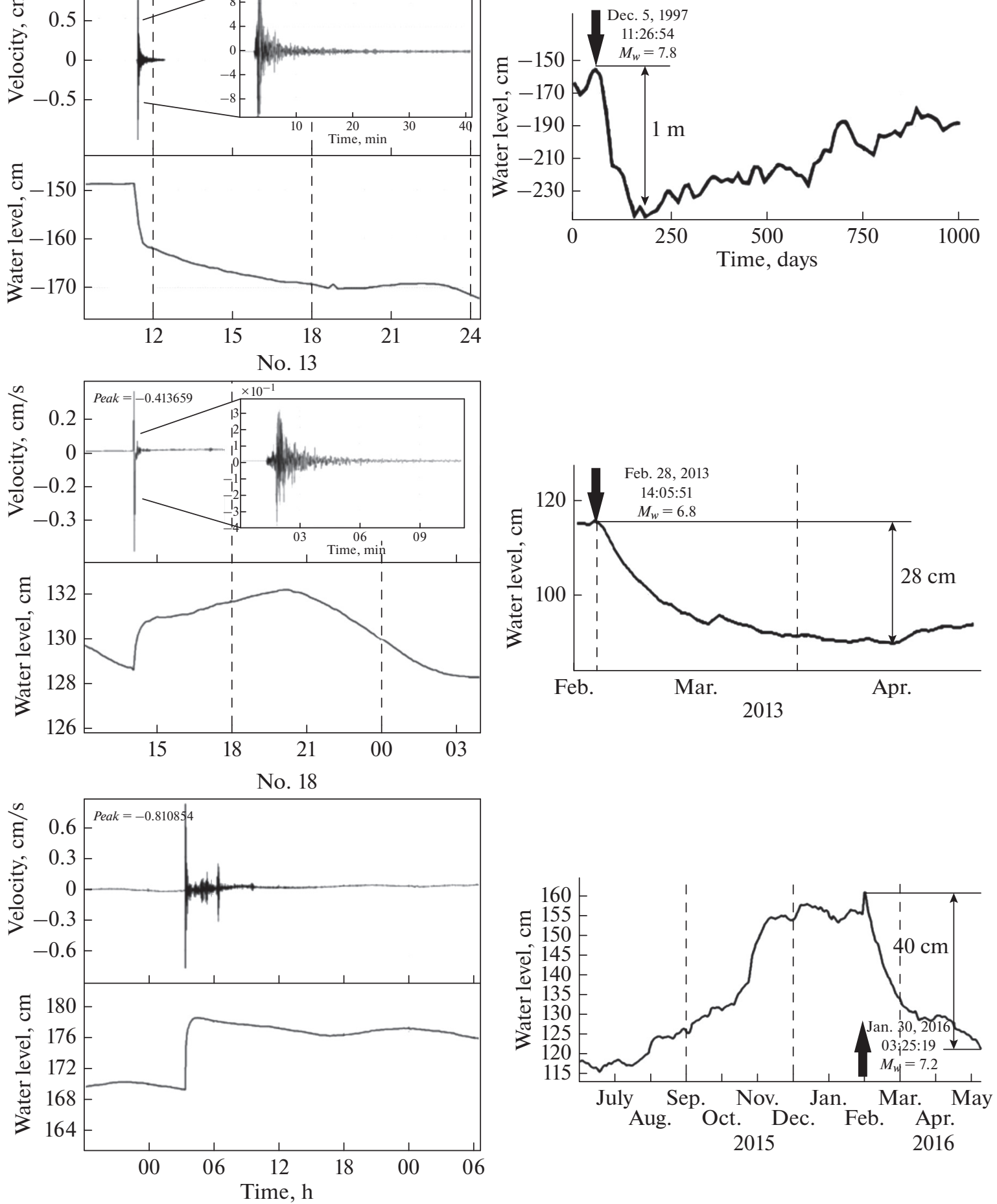

Fig. 5. Type IV hydrogeoseismic variations of water level in YuZ-5 well compared with e earthquake records in BHZ channel, PET. Earthquake numbers correspond to Table 1 and Fig. 1.

distributions suggest that with the increase in the intensity of seismic impact on the well- water-bearing rock system, a regular change is observed in its response to the passage of seismic waves, and with the increase in $e$ и $V_{m}$, the HGSV types successively change from I to IV. 
Sept. 8, 2017, $M_{w}=8.2$, Mexico

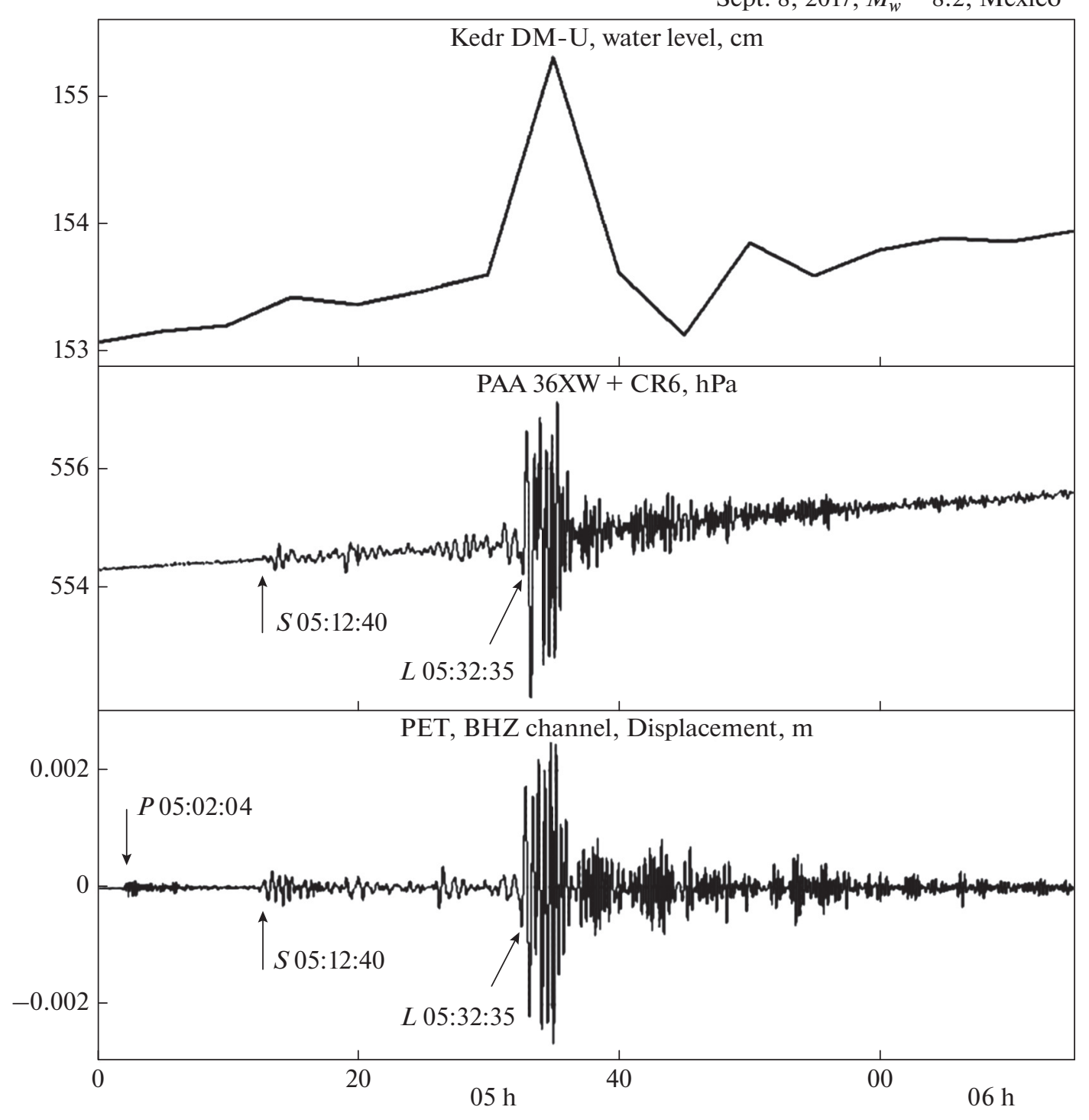

Fig. 6. Water level variations measured every $5 \mathrm{~min}(\mathrm{Kedr} \mathrm{DM})$ and groundwater pressure at depth of $5.6 \mathrm{~m}$ with sampling frequency $10 \mathrm{~Hz}$ (PAA 36XW sensor) in YuZ-5 well during earthquake of September 9, 2017, $M_{w}=8.2$, Mexico (no. 19 in Table 1) compared with displacement record in the BHZ channel, PET.

Besides, we analyzed the records of all the 19 earthquakes recorded by STS-1 three-component broadband sensor at PET station. Based on these records, with the use of their emulation and filtering in the different frequency ranges in the DIMAS program (Droznin and Droznina, 2010), we estimated the peak ground velocities (Table 2), peak ground accelerations and peak ground displacements in BHN, BHE, BHZ channels during passage of seismic waves.

The records of the earthquakes accompanied by HGSV types I - III (tables 1 and 2) are characteristically marked by the presence of intense manifestations of surface waves (Fig. 2 - Fig. 4). The peak ground velocities in the case of these earthquakes were estimated using bandpass filtering with a set of filters $F=10$ in the frequency range from 0.01 to $0.1 \mathrm{~Hz}$. Figure 8 shows an example of bandpass filtering of the record of ground particle displacement velocities in BHN channel during the earthquake of December 26, 2004 (no. 3 in Fig. 1, tables 1 and 2). The peak ground velocity in BHN channel during this earthquake was $0.316 \mathrm{~cm} / \mathrm{s}$ (Fig. 8, left diagram) and corresponded to the center frequency of $0.04 \mathrm{~Hz}$ (Fig. 8, right diagram).

In the records of local earthquakes accompanied by type IV HGSV (nos. 1, 13 and 18 in Fig. 1 and Table 1), surface waves were not observed (Fig. 5). The peak ground velocities for these earthquakes were estimated from the body $S$-waves using bandpass filtering in the frequency range from 0.01 to $0.3 \mathrm{~Hz}$ with a set of filters 


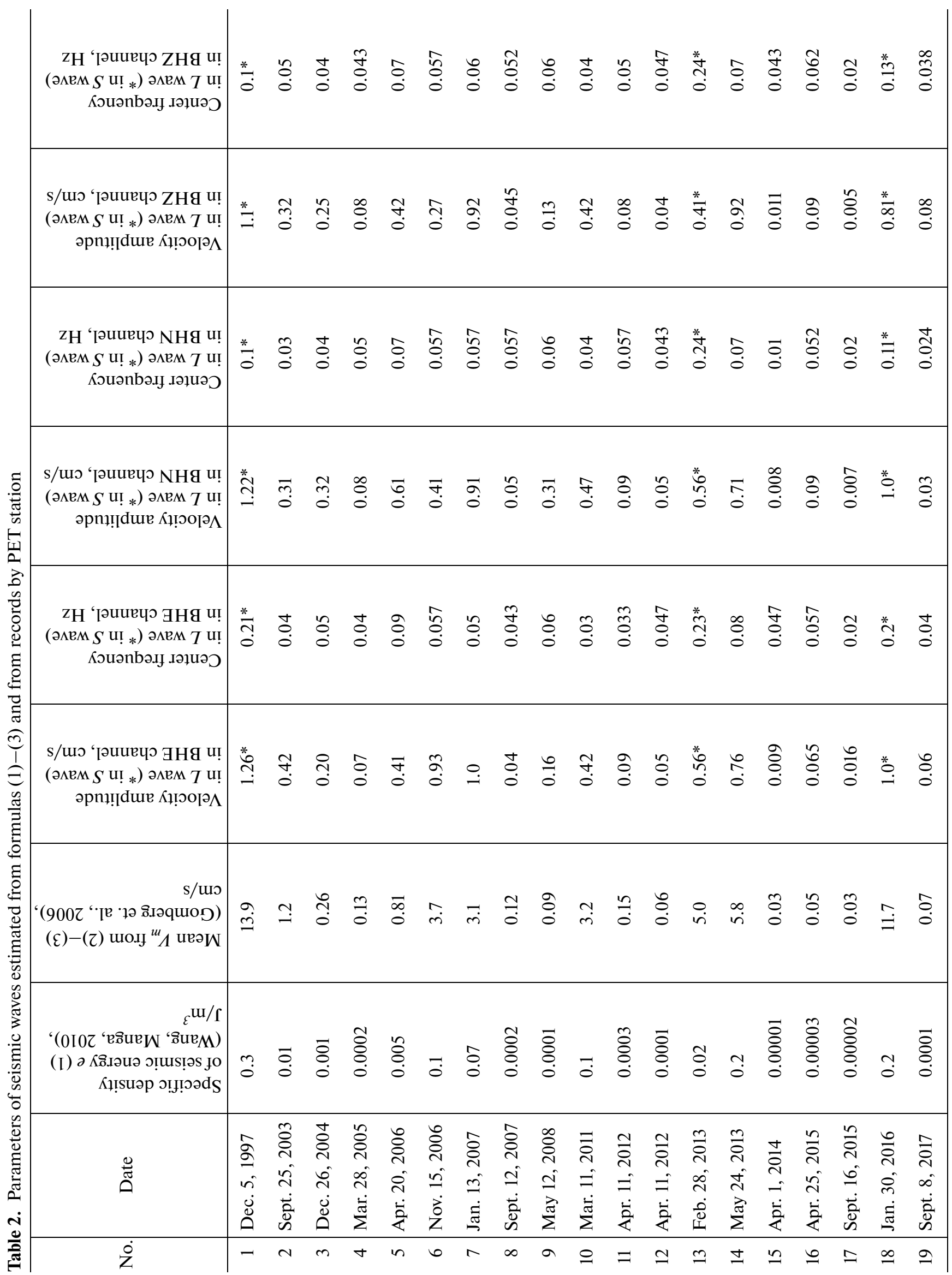



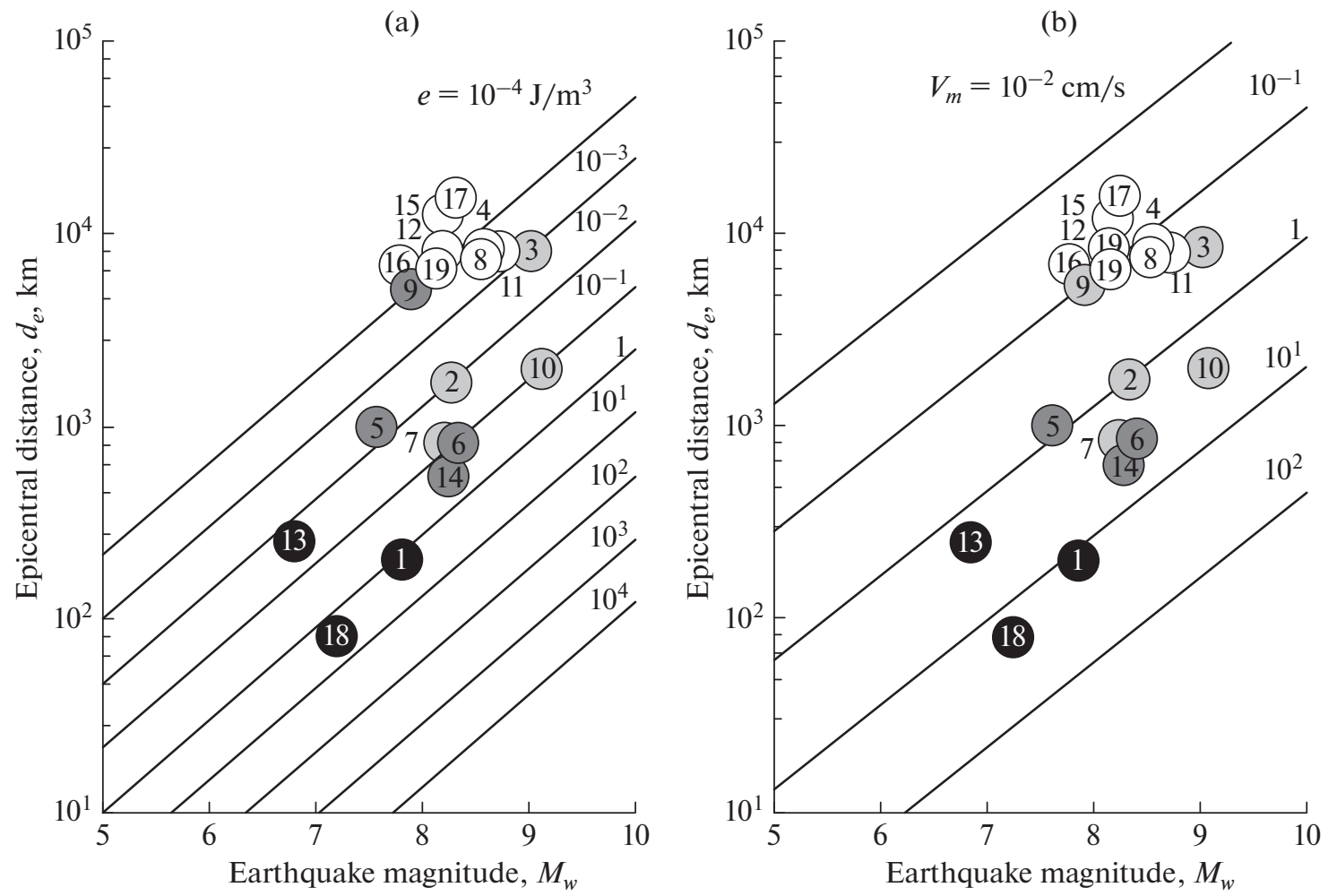

Fig. 7. Distribution of identified HGSV types in YuZ-5 well (type I-white circles, type II-gray, type III-dark gray, type IV—black) depending on (a) earthquake parameters $M_{w}$ and $d_{e}$, seismic energy density in wave $e$ and (b) peak ground velocity $V_{m}$. Figures are earthquakes numbers according to tables 1,2 and Fig. 1, Figs. 2-5.

from $F=10$ to $F=15$ for more accurate determining the center frequency.

As a result of this processing of seismic records, for each of the 19 earthquakes we obtained the estimates of peak ground velocities in three channels and their center frequencies (Table 2). Figure 9 shows the distributions of HGSV of types I-IV depending on the parameters of amplitude-frequency content of the maximum phases of the ground motion velocity at PET in three channels. The positions of the circles of HGSV of types I-IV on the horizontal axis correspond to the center frequencies of the passband of a seismic record filtering in which the maximum ground velocities were detected (Table 2).

The pattern of the distribution of HGSV types IIV (Fig. 9) demonstrates evident correlation between the occurrence of their individual types depending on the amplitude-frequency content of the maximum phases of the ground motion at the nearest seismic station. Here, the low-frequency and low-amplitude seismic signals under the passage of surface waves are accompanied by the oscillations of the water level (type I HGSV). With the increase in the amplitude of seismic signal, the oscillatory pattern of water level fluctuations can be superimposed by short rises of the water level (type II HGSV). The relatively high-frequency surface wave signals are accompanied by short rises in the water level (type III HGSV). With the increase in the amplitude of the signal in the records of body waves, in the cases of the strongest local earthquakes accompanied by perceptible shaking with $I_{\text {msk-64 }}$ intensity of at least 5-6, sustained (months long) drawdowns are observed in the water level (type IV HGSV).

\section{HGSV TYPES I-IV FORMATION PROCESSES}

The processes responsible for the formation of type I-IV HGSV in the SW-5 well were studied based on the comparison of the observed water level variations with the predicted behavior calculated from the mathematical models (Cooper et al., 1965; Roeloffs, 1998; Brodsky et al., 2003) with the allowance for the parameters of water-bearing rocks and geometrical dimensions of the well. This approach makes it possible to obtain quantitative criteria for the conditions of occurrence and development of various hydrogeodynamic processes under the influence of seismic waves and to construct phenomenological models of HGSV formation for a real observation well (Boldina and Kopylova, 2010; 2013; Boldina, 2017).

In (Cooper et al., 1965) it was shown that water level oscillations in a well (HGSV types I and II (Figs. 2 and 3)) are caused by two factors: (a) harmonic variations in groundwater pressure under dynamic deformation of 


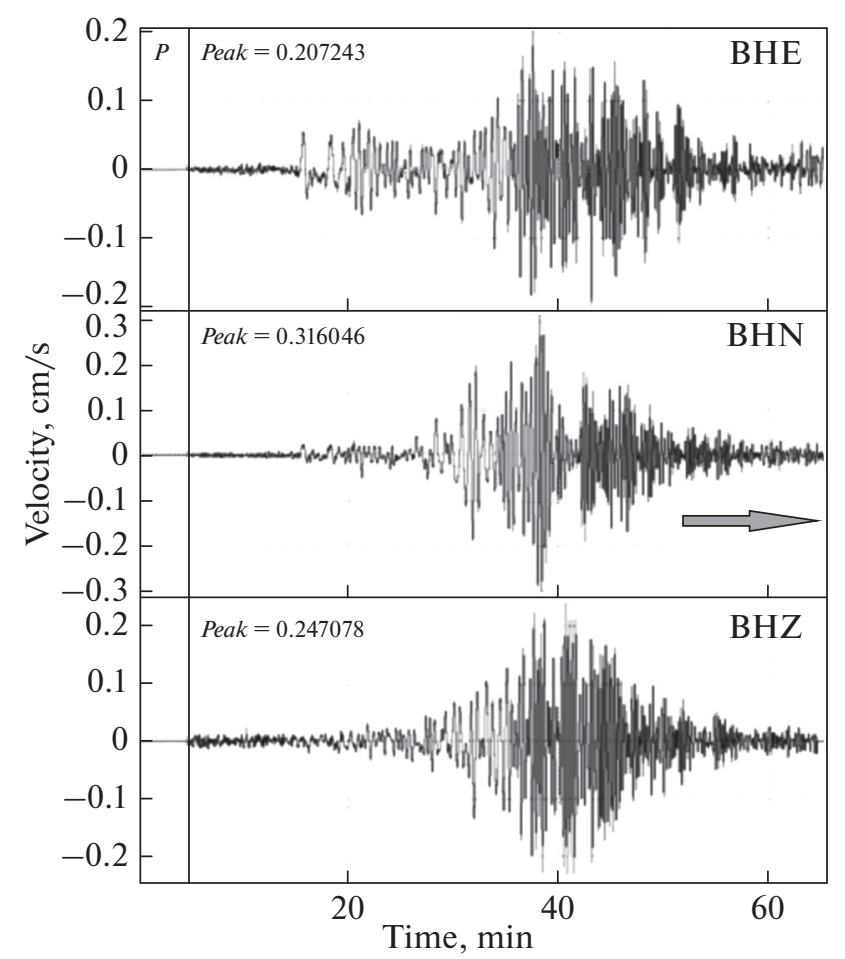

Dec. $26,2004, M_{w}=9.0, H=30 \mathrm{~km}, d_{e}=8260 \mathrm{~km}$

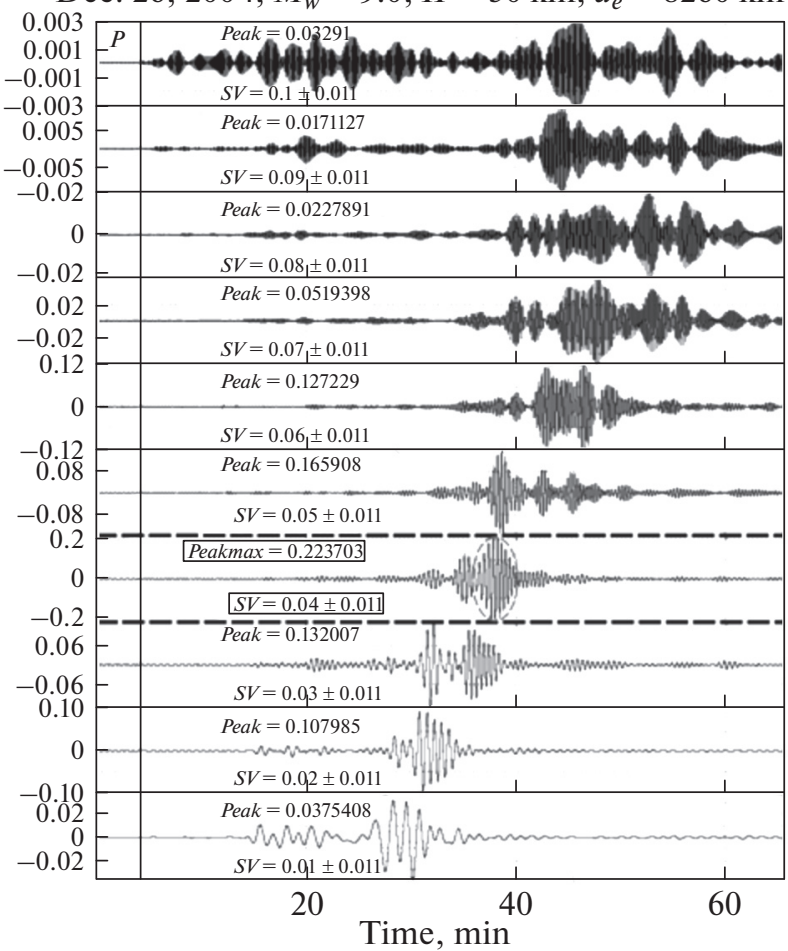

Fig. 8. Records of earthquake of December 26, 2004 (no. 3 in tables 1 and 2) in BHE, BHN and BHZ channels at PET with peak ground amplitudes Peak (left diagram) and band-pass filtering of ground motion velocity in BHN channel in DIMAS program (right diagram). Heavy dashed line limits frequency band $\mathrm{SV}=0.04 \pm 0.011 \mathrm{~Hz}$ where maximal peak ground velocity amplitude Peakmax $=0.2237 \mathrm{~cm} / \mathrm{s}$ is detected (shown by ellipse).

water-bearing rocks and (b) vertical displacements of the ground surface and the wellbore. Here, the intensity of water level response to the passage of seismic waves is determined by the geometric characteristics of the well, transmissivity, and elastic capacity of waterbearing rocks, and also depends on the type and period of seismic waves.

Water level oscillations in SW-5 well were described by the analytical formula specifying the amplitude ratio between the water level variations $x_{0}$ and the head $h_{0}$ with the allowance for the resonant amplification of groundwater pressure variations in the well-waterbearing rock system under the passage of surface seismic waves (Cooper et al., 1965; Kopylova and Boldina, 2007; Boldina, 2017):

$$
\begin{aligned}
A=x_{0} / h_{0} & =\left[\left(1-\frac{\pi r_{w}^{2}}{T \tau} \operatorname{Kei\alpha }_{w}-\frac{4 \pi^{2} H_{e}}{\tau^{2} g}\right)^{2}\right. \\
+ & \left.\left(\frac{\pi r_{w}^{2}}{T \tau} \operatorname{Ker}_{w}\right)^{2}\right]^{-1 / 2},
\end{aligned}
$$

where $H_{e}$ is the effective height of water column in a well: $H_{e}=H+3 d / 8$ (where $H$ is the height of water column in a cased wellbore; $d$ is the height of water column in the zone of penetration of water-bearing rocks); $\tau$ is the period of seismic wave, $\alpha_{w}=r_{w}(\omega S / T)^{1 / 2}$ is the dimensionless function of frequency expressed in terms of the parameters of the water-bearing rocks and the geometric dimensions of the well ( $T$ is the transmissivity, $S$ is elastic capacity of water-bearing rocks, $r_{w}$ is the radius of the well in the region of its connection with water-bearing rocks, and $\omega$ is angular frequency of seismic wave); Ker $\alpha_{w}, K_{e i \alpha_{w}}$ are the real and imaginary parts of the Kelvin function of zero order.

In Fig. 10, based on the case study of the SumatraAndaman earthquake of December 26, 2004, $M_{w}=9.1$ (no. 3 in Table 1, Fig. 3), we consider the emergence of water level oscillations in the YuZ-5 well which significantly exceed the vertical ground surface displacement $\left(x_{0} / h_{0}>1\right)$. This example shows that the groundwater pressure oscillations in the well intensify under the passage of surface seismic waves with period $\tau=$ $44.6 \mathrm{~s}$ and parameter $T / r_{w}^{2} \geq 1 \mathrm{~s}^{-1}$ (Kopylova and Boldina, 2007). In the cited work, we presented the values of the parameters for the YuZ-5 well $T=0.9 \times 10^{-4} \mathrm{~m}^{2} / \mathrm{s}$, $S=18.7 \times 10^{-5} \mathrm{~m}^{-1}, r_{w}=0.084 \mathrm{~m}$ and the effective height of water column in the well $H_{e}=494 \mathrm{~m}$ at which the resonant enhancement in the groundwater pressure variations in the wellbore was observed.

Short rises of the water level after the arrival of seismic waves (type III HGSV, Fig. 4) reflect the pulsed 

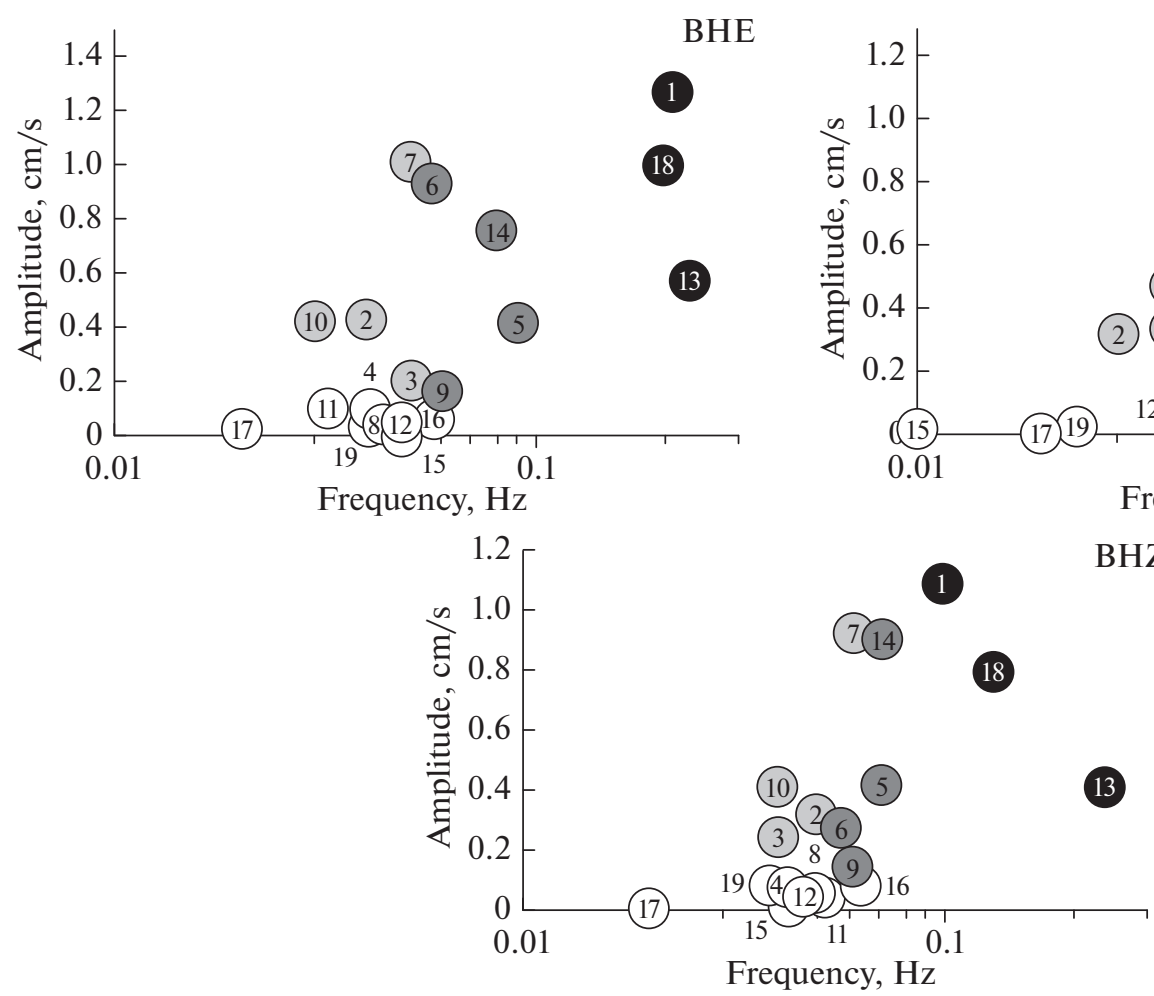

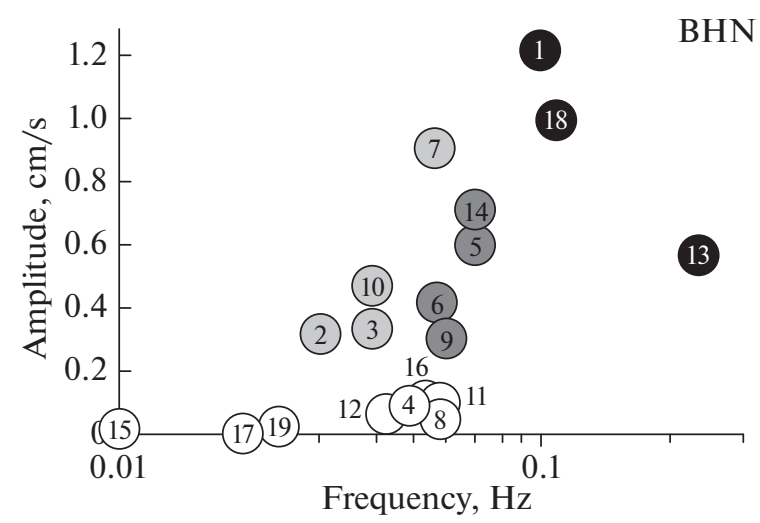

$\mathrm{BHZ}$

ig. 9. Distribution of different HGSV types (type I - white circles, type II - gray, type III — dark gray, type IV—black) depending on peak ground velocity in BHE, BHN and BHZ channels at PET and center frequency of its occurrence. Figures are earthquake numbers according to tables 1,2 and Fig. 1, Figs. 2-5.

increase in the groundwater pressure under the emergence of the effect of nonlinear filtration in the vicinity of the well accompanied by water inflow into its wellbore. As shown in (Kocharyan et al., 2011), these effects may arise in the presence of local inhomogeneities in the filtration properties of the water-bearing rocks penetrated by the well.

The rises in the water level (Fig. 4) caused by the pulsed increases in pressure were described by an exponentially decaying function characterizing the water flow process without specifying the spatial changes in the pressure field responsible for water inflow into the well (Roeloffs, 1998):

$$
u(t)=u_{0}\left(1-\exp \left(-t / t_{r}\right)\right),
$$

where $u_{0}$ is the maximum amplitude of the rise in the head of groundwater, $t$ is time, $t_{r}$ is the parameter of pressure relaxation time in the well-water-bearing rock system.

Figure 11 shows the calculated rises in the water level in the YuZ-5 well within two hours after the arrival of seismic waves from the Olyutora earthquake of April 20, 2006, $M_{w}=7.6$ (no. 5 in Table 1, Fig. 4). The calculated rise of the water level fairly well agrees with the observed data at the amplitude of the rise in the head of groundwater $u_{0}=1.6 \mathrm{~cm}$ and pressure relaxation time $t_{r}=14 \mathrm{~min}$.
Sustained water level drawdowns as a result of the strong local earthquakes (Type IV HGSV, Fig. 5) can be caused by the drop in the groundwater pressure due to local or regional increase in permeability of water-bearing rocks under seismic shaking of intensity $I_{\text {msk-64 }} \geq 5$. These water level drawdowns are described by the mathematical model of a remote point source of head perturbation in an aquifer (Brodsky et al., 2003; Boldina and Kopylova, 2010; 2013; 2017; Boldina, 2017):

$$
x=x_{0}-\Delta h \operatorname{erf} c(R / \sqrt{4 c t}),
$$

where $x$ is the water level in well; $x_{0}$ is the initial water level in well; $R$ is the distance from the well to the source of the drop in pressure; $c$ is the piezoconductivity; $t$ is the duration of the drawdown of water level; $\operatorname{erf} c(x)$ is the complement of the error function $\operatorname{erf}(x)$ to 1 , i.e. $\operatorname{erf} c(x)=1-\operatorname{erf}(x)=\frac{2}{\sqrt{\pi}} \int_{0}^{x} \exp \left(-u^{2}\right) d u$.

Figure 12 illustrates the water level decrease with an amplitude $\Delta h=0.40 \mathrm{~m}$ during three months after the Zhupanovky earthquake of January $30,2016, M_{w}=7.2$ (no. 18 in Table 1, Fig. 5) calculated according to (7). This water level drawdown could take place at piezoconductivity of water-bearing rocks $c=0.24 \mathrm{~m}^{2} / \mathrm{s}$ and a distance between the well and the source of the drop in the head $R=450 \mathrm{~m}$ (Boldina and Kopylova, 2017; Boldina, 2017). The calculations of the water level 


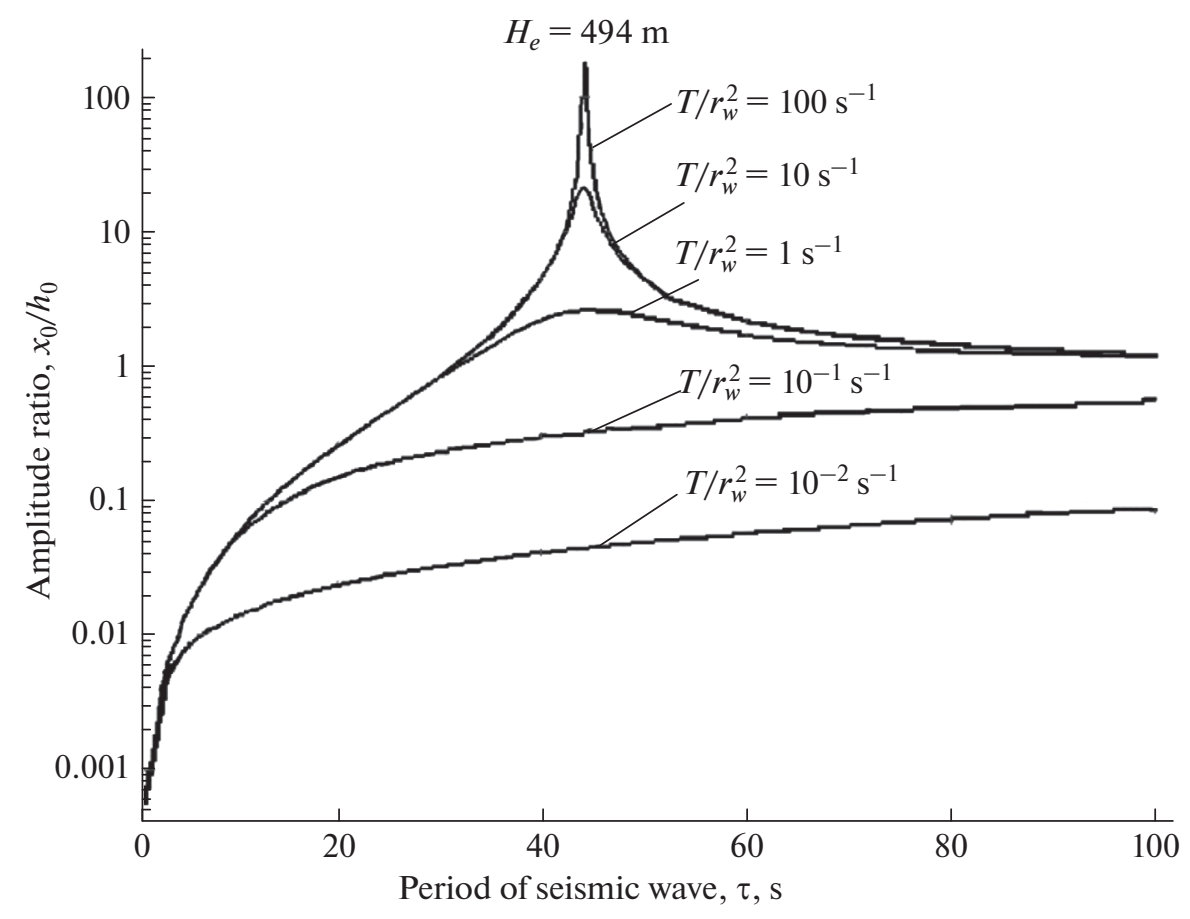

Fig. 10. Changes in the amplitude ratio between water level variations $x_{0}$ and groundwater head $h_{0}$ as function of period $\tau$ of seismic wave, transmittivity $T$, and well radius in area of its communication with water-bearing rocks $r_{w}$.

drawdown by formula (7) after the Kronotsky earthquake of December 12, 1997, $M_{w}=7.8$ (mo. 1, Fig. 5) and after the earthquake of February 28, 2013, $M_{w}=$ 6.8 (no. 13, Fig. 5) are consistent with the result presented above (Fig. 12) in terms of estimating the piezoconductivity of water-bearing rocks and determining the distance to the source of the head fall. In all cases, the distances to the source of the head fall were the same, $R=450 \mathrm{~m}$ (Boldina and Kopylova, 2010; 2013; 2017). This may indicate that at a distance of about $450 \mathrm{~m}$ from the well there is a geological object, e.g., a fault zone or another type of a hydrogeological "window" whose water permeability sharply increases under seismic shaking with intensity 5 or higher on the MSK-64 scale. For making more reasonable assumptions about the nature of these objects and their behavior during the intense seismic shaking as well as for refining the structure of the medium in the vicinity of the YuZ-5 well, it is necessary to conduct a field survey of the territory with the use of geophysical methods.

\section{DISCUSSION OF RESULTS AND CONCLUSIONS}

\section{HGSV Typification and Its Validity}

Based on the long-term detailed observations of water level variations in the SW-5 well, we identified four types of HGSV arising under the action of seismic waves emitted from the sources of the strong local and remote earthquakes. It has been possible to achieve this result due to the persistent continuity and high accuracy of water level measurements during a long period of time and due to using the specialized software products of the POLYGON Information System (Kopylova et al., 2009) and DIMAS data processing and visualization program (Droznin and Droznina, 2010), which are suitable for analyzing water level changes within a wide time span (from minutes to days and months) and for comparing the identified HGSV with the time of arrival of various groups of seismic waves.

At the same time, based on the water level measurements taken with an interval of 5-10 minutes it proved to be possible to obtain only approximate estimates of the amplitudes and duration of water level oscillations during the occurrences of HGSV types I and II (Table 1). Despite this methodological limitation, the identification of the HGSV types I and II based on the existing technical means is consistent with the data of high-frequency pressure measurements in the YuZ-5 well (Fig. 6) and with the data of similar observations in the other seismically active regions in the wells penetrating the consolidated water-bearing rocks, discussed in the Introduction.

The experience of recording four different HGSV types in a single one well which is presented in this work is unique.

In our opinion, the prospects for the further study of HGSV are related with introducing in the practical research the technical means for recording the 


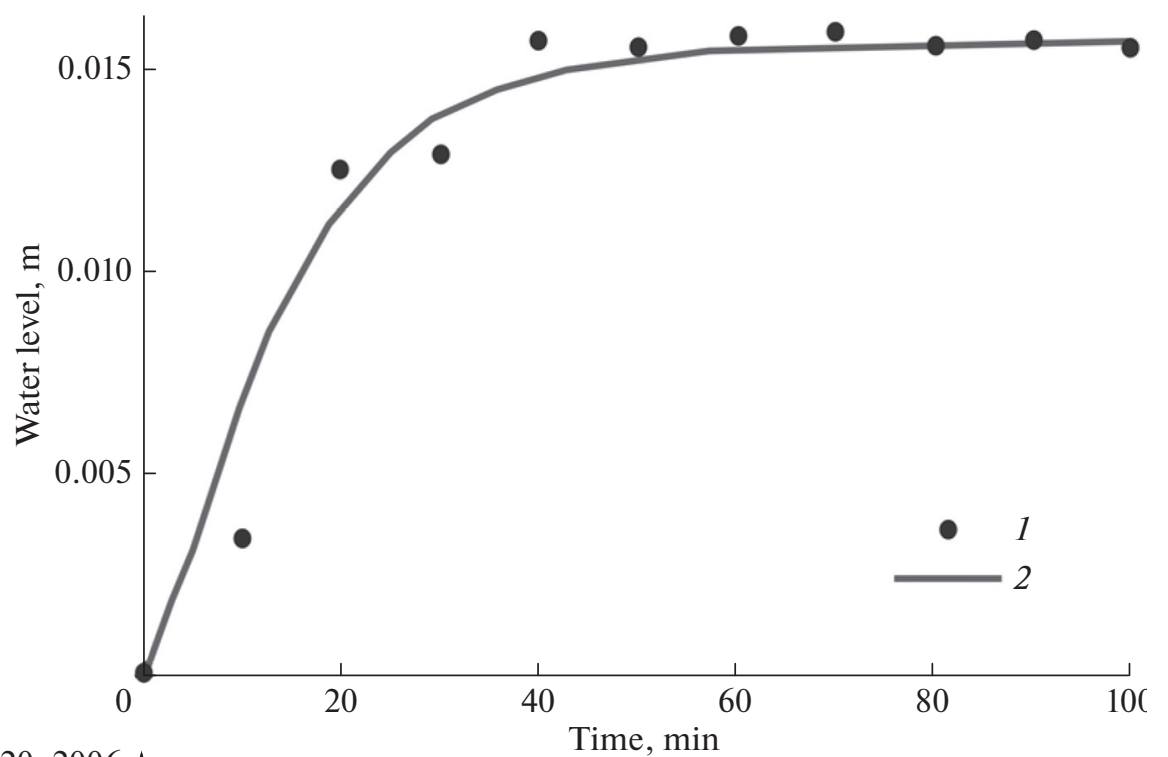

April 20, 2006
$M_{w}=7.6$
$d_{e}=1018 \mathrm{~km}$

Fig. 11. Water level rise in YuZ-5 well during two hours after the seismic waves arrival during Olyutorskoe earthquake of April 20 , 2006, $M_{w}=7.6$ (no. 5 in Table 1, shown by arrow): 1, 10-min observation data; 2, water level rise estimated by formula (6).

groundwater pressure in wells with sampling frequency of at least tens of $\mathrm{Hz}$, corresponding to the degree of detail of seismic observations.

\section{Occurrence of Different HGSV Types Depending on the Intensity of Seismic Impact}

In Fig. $7 \mathrm{a}$ and $7 \mathrm{~b}$ it is shown that the occurrence of the four HGSV types revealed by their morphological features is determined by the parameters of the earthquakes, namely, by the ratio between the magnitude $M_{w}$ and epicentral distance $d_{e}$ of the earthquake as well as by the specific energy density $e$ in a seismic wave and peak ground velocities $V_{m}$ in this wave. The used set of the quantitative characteristics of the earthquake can be considered as an integral indicator reflecting the intensity of the influence caused by seismic waves emitted from seismic source on the observation well. In the case of a strong earthquake that occurs at a distance up to thousands $\mathrm{km}$ from the well, based on $M_{w}$, $d_{e}, e$ and $V_{m}$, it is possible to predict the character of HGSV development in the YuZ-5 and in other similar wells, which expands the potential of water level observations in the system of geophysical monitoring in seismically active regions.

The calculated estimates of parameters $e$ and $V_{m}$ need to be independently verified for the YuZ-5 well. In Table 2, we present the calculated $V_{m}$ values and the estimates of the peak ground velocities recorded in the BHN, BHE, BHZ channels at PET seismic station, which fairly well agree with each other for most of the considered earthquakes. The only exception is the strongest earthquakes (Nos. 1, 10, 13, 14 and 18) for which the calculated values $V_{m}=3.2-13.9 \mathrm{~cm} / \mathrm{s}$ are times larger (by up to as much as a factor of ten) than the velocities recorded at PET. This is due to the specificities of operation of STS-1 velocimeters in the IRIS measurement system for which the amplitude range is limited to a maximum velocity of $1 \mathrm{~cm} / \mathrm{s}$.

Unfortunately, we are not able to obtain independent estimates of specific energy density $e$ in the wave for the region of the YuZ-5 well.

\section{Peculiarities of Hydrogeodynamic Processes in a Well-Water-Bearing Rock System under the Influence of Seismic Waves}

As shown above, depending on the intensity of seismic impact and on the amplitude-frequency content of maximal phases of ground motion under the passage of seismic waves, different HGSV types can appear, caused by the emergence and development of specific hydrogeodynamic processes in the considered well-water-bearing rock system (Figs. 7 and 9). We considered several types of these processes.

(1) Harmonic variations in the groundwater pressure and in the movement of a water column in well are considered based on the mathematical model (Cooper et al., 1965). Water level oscillations in the YuZ-5 well with amplitudes equal to or above $0.5 \mathrm{~cm}$ arise under the action of surface waves with peak ground velocities of the order of $0.2-0.5 \mathrm{~cm} / \mathrm{s}$ at frequencies of $0.06-0.01 \mathrm{~Hz}$ (periods from 16 to $100 \mathrm{~s}$, 


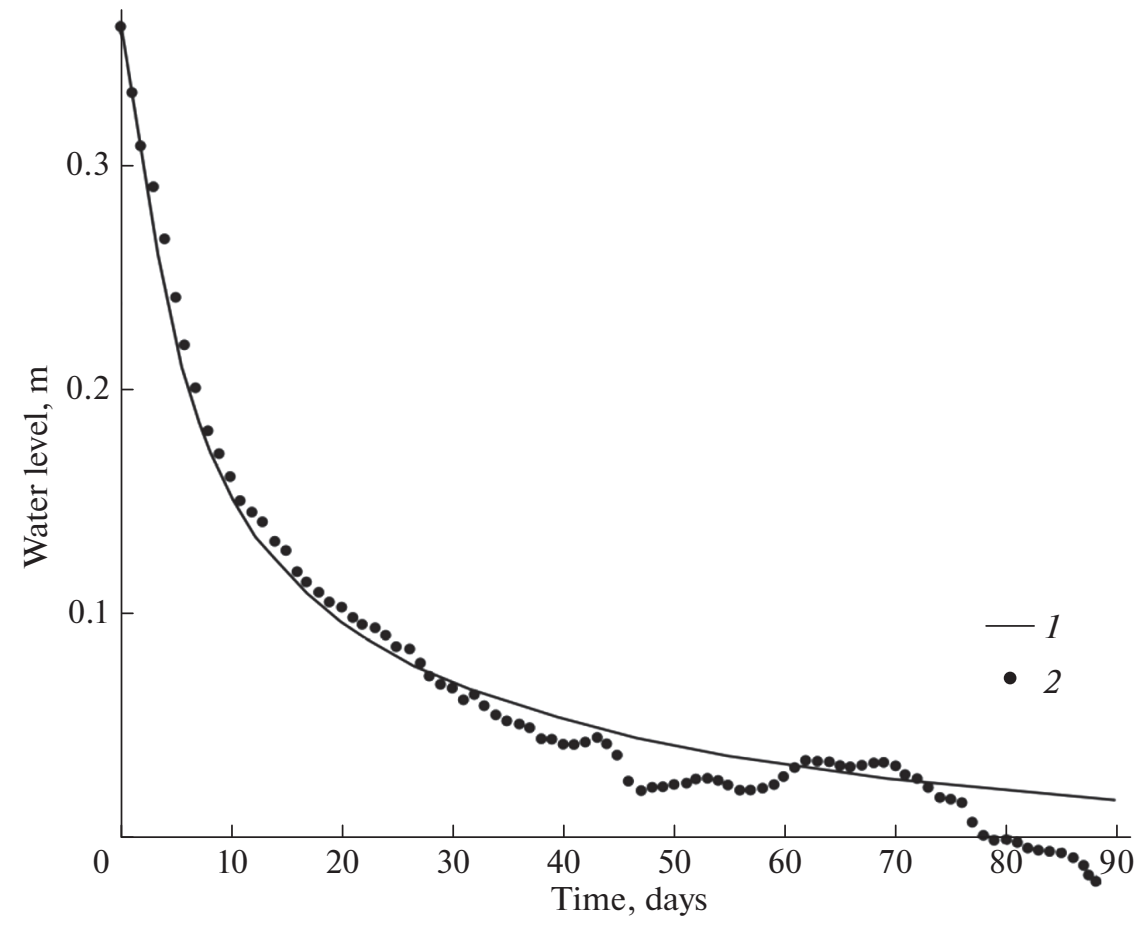

Fig. 12. Modeling results for water level drawdown in YuZ-5 well during three months after Zhupanovsky earthquake of January 30 , 2016, $M_{w}=7.2$ (no. 18 of Table 1): 1, daily average observation data with compensated barometric and seasonal variations; 2 , water level drawdown estimated by (7).

Fig. 9). The numerical modeling of the hydrogeodynamic process during the Sumatra-Andaman earthquake (Fig. 10) has shown that the effect of surface waves at a period of $44.6 \mathrm{~s}$, corresponding to the resonant frequency of the well, can be accompanied by the enhancement of groundwater pressure variations in the well and water level fluctuations with amplitudes up to a few to several tens $\mathrm{cm}$ lasting for a few hours to one day.

(2) With the increase in the velocity and frequency of the maximum phases of seismic signal (HGSV types II and III), the effect of a pulsed increase in the groundwater pressure with amplitudes of the order of the first $\mathrm{cm}$ of water column arises in the vicinity of a wellbore.

(3) Under the influence of high-frequency body waves from the strong local earthquakes accompanied by ground shaking intensity 5-6, the groundwater pressure drops with the amplitudes up to $0.1 \mathrm{bar}$ at a distance of up to a few hundred meters from the well.

The examples of HGSV modeling based on the well-known mathematical models and the data on the parameters of water-bearing rocks and the design features of a well demonstrate the possibility of analyzing the hydrogeodynamic processes of the formation of different HGSV types in the considered well-waterbearing rock system with obtaining the quantitative criteria for the initiation and development of these HGSV types.
In the case of the YuZ-5 well, the HGSV types I and II arise due to the shaking of the wellbore, dynamic deformation of the water-bearing rocks, and harmonic oscillations of the groundwater pressure in the well-water-bearing rock system. Under the passage of surface seismic waves with the periods corresponding to the resonant frequency of the well $(\sim 0.023 \mathrm{~Hz})$, the effect of groundwater pressure oscillations enhancement in the wellbore may appear. We note that we did not consider the probable effect of emergence of water pressure oscillations due to elastic change in the volume of water in the well in response to the passage of seismic waves, which has been recently considered in the interpretation of the high-frequency pressure records in closed wells, in particular, in (Shalev et al., 2017a).

The rise of the level for tens of minutes to hours after the passage of seismic waves (HGSV types II and III) is caused by a short increase in pressure due to the violation of the steady water flow conditions in the zone immediately adjacent to the wellbore.

A sustained water level drawdown (type IV HGSV) is observed after sensible earthquakes $\left(I_{\text {msk-64 }} \geq 5\right)$ and, apparently, is caused by the increase in the permeability of water-bearing rocks accompanied by a fall in the groundwater pressure with amplitudes of $0.03-0.1$ bar within a radius of hundreds of meters from the well. This conclusion is consistent with the data of (Zhang et al., 2018) where the authors analyze a month-long 
water level drawdown in the MP well, China, after the earthquake of May 12, 2008 (no. 9 in Fig. 1, Table 1) using different models of hydrodynamic processes, each formally providing a good agreement between the calculated and observed data. At the same time, based on the integrated analysis of the modeling results and empirical data on the variations in tidal response of water level in the MP well, the authors indicated the mechanism of temporal increase in the permeability of water-bearing rocks as a most plausible one for explaining the sustained post-seismic water level decrease.

The analysis of the set of co- and post-seismic effects in the water level changes in well YuZ-5 conducted in this work shows that under the influence of seismic waves from the strong earthquakes, specific hydrogeodynamic processes appear in the wellwater-bearing rock system, accompanied by the groundwater head variations, episodes of non-linear filtration, local and areal changes in the filtration properties of water-bearing rocks, and, perhaps, changes in the groundwater composition.

\section{ACKNOWLEDGMENTS}

We are grateful to the Geological Survey of Israel (GSI) and personally to director Rivka Amit, head of the department pf water and natural resources Eyal Shalev, senior researcher Vladimir Lyakhovsky and field technician Halel Lutsky for providing equipment for high-frequency water level recording in YuZ-5 well and useful consulting on its installation and operation.

\section{FUNDING}

The work was supported by the Russian Foundation for basic Research under project 18-05-00337 "Typification and models of hydrogeoseismic effects of the earthquakes from water level measurements in wells: case study of Kamchatka region".

\section{REFERENCES}

Adushkin, V.V. and Spivak, A.A., Fizicheskie polya v pripoverkhnostnoi geofizike (Physical Fields in Near-Surface Geophysics), Moscow: GEOS, 2014.

Besedina, A., Vinogradov, E., Gorbunova, E., and Svintsov, I., Chilean earthquakes: Aquifer responses at the Russian platform, Pure Appl. Geophys., 2016, vol. 173, pp. 1039-1050.

https://doi.org/10.1007/s00024-016-1256-5

Boldina, S.V., Effekty zemletryasenii v sisteme "skvazhinavodovmeshchayushchaya poroda" (The Effects of Earthquakes in the System "Well - Reservoir Rock"), Saarbrücken: LAP Lambert Acad. Publishing, 2017.

Boldina, S.V. and Kopylova, G.N., Modeling hydrogeoseismic water level variations in a well, Trudy Vtoroi regional'noi nauchno-tekhnicheskoi konferentsii "Problemy kompleksnogo geofizicheskogo monitoringa Dal'nego Vostoka Rossii” (Proc. 2nd Regional Scientific and Technical Conference "Problems of Integrated Geophysical Monitoring of the Russian Far East"), Petropavlovsk-Kamchatskii, 2009, Petropavlovsk-Kamchatskii: GS RAN, 2010, pp. 166-170.

Boldina, S.V. and Kopylova, G.N., Modeling of water level variations in the YuZ-5 well, Kamchatka, caused by the earthquake of February 28, 2013, M=6.8, Trudy Chetvertoi nauchno-tekhnicheskoi konferentsii "Problemy kompleksnogo geofizicheskogo monitoringa Dal'nego Vostoka Rossii” (Proc. 4th Scientific and Technical Conference "Problems of Integrated Geophysical Monitoring of the Russian Far East"), Petropavlovsk-Kamchatskii, 2013, Obninsk: GS RAN, 2013, pp. 435-439.

Boldina, S.V. and Kopylova, G.N., Effects of the January 30, 2016, $\mathbf{M}_{\mathrm{w}}=7.2$ Zhupanovsky earthquake on the water level variations in wells YuZ-5 and E-1 in Kamchatka, Geodinam. Tektonofiz, 2017, vol. 8, no. 4, pp. 863-880. https://doi.org/10.5800/GT-2017-8-4-0321

Bower, D. and Heaton, K., Response of an aquifer near Ottawa to tidal forcing and the Alaskan earthquake of 1964, Can. J. Earth Sci., 1978, vol. 15, pp. 331-340.

Brodsky, E.E., Roeloffs, E., Woodcock, D., Gall, I., and Manga, M.A., A mechanism for sustained groundwater pressure changes induced by distant earthquakes, J. Geophys. Res., 2003, vol. 108, pp. 2390-2400.

https://doi.org/10.1029/2002JB002321

Chelidze, T., Melikadze, G., Kobzev, G., Shengelia, I., Jorjiashvili, N., and Mepharidze, E., Hydrodynamic and seismic response to teleseismic waves of strong remote earthquakes in Caucasus, Acta Geophys., 2019, vol. 67, pp. $1-16$.

https://doi.org/10.1007/s11600-018-00241-7

Chia, Y., Chiu, J.-J., Chiang, Y.-H., Lee, T.-P., Wu, Y.-M., and Horng, M.-J., Implications of coseismic groundwater level changes observed at multiple-well monitoring stations, Geophys. J. Int., 2008, vol. 172, pp. 293-301. https://doi.org/10.1111/j.1365-246X.2007.03628.x

Cooper, H.H., Bredehoeft, J.D., Papadopulos, I.S., and Bennet, R.R., The response of well-aquifer system to seismic waves, J. Geophys. Res., 1965, vol. 70, pp. 3915-3926.

Droznin, D.V. and Droznina, S.Ya., Program for seismic signal processing DIMAS, Seism. Prib., 2010, vol. 46, no. 3, pp. 22-34.

Gomberg, J., Felzer, K., and Brodsky, E., Earthquake dynamic triggering and ground motion scaling, Proc. 4th Int. Workshop on Statistical Seismology, Kanagawa, Japan, 2006, pp. 45-51.

Kanamori, H. and Brodsky, E.E., The physics of earthquakes, Rep. Prog. Phys., 2004, vol. 67. pp. 1429-1496.

Kasimova, V.A. and Kopylova, G.N., On the dependence of water level variations during severe earthquakes on the amplitude-frequency composition of the maximum phases of soil movements (using the example of SW-5, Kamchatka), Materialy Sed'moi Mezhdunar. seismol. shkoly "Sovremennye metody obrabotki i interpretatsii seismologicheskikh dannykh" (Proc. 7th Int. Seismol. School "Modern Methods of Processing and Interpretation of Seismological Data"), Naroch, Belarus, 2012, Obninsk: GS RAN, 2012, pp. 143-147. Kissin, I.G., Hydrogeological monitoring of the Earth's crust, Izv. Ross. Akad. Nauk, Fiz. Zemli, 1993, no. 8, pp. 58-69. 
Kocharyan, G.G., Markov, V.K., Markov, D.V., and Pernik, L.M., On the mechanism of variations in the fluid dynamics of underground reservoirs under the influence of weak perturbations, in Fizicheskie polya i dinamika vzaimodeistvuyushchikh geosfer: Sbornik nauchnykh trudov IDG $R A N$ (Physical Fields and Dynamics of Interacting Geospheres: Collection of Papers of the IDG RAS), Moscow: GEOS, 2007, pp. 56-65.

Kocharyan, G.G., Vinogradov, E.A., Gorbunova, E.M., Markov, V.K., Markov, D.V., and Pernik, L.M., Hydrologic response of underground reservoirs to seismic vibrations, Izv. Phys. Solid Earth, 2011, vol. 47, no. 12, pp. 1071-1082.

Kopylova, G.N., Variations of water level in Elizovskava-1 well, Kamchatka due to large earthquakes: 1987 -1998 observation, Vulkanol. Seismol., 2001, no. 2, pp. 39-52.

Kopylova, G.N., Earthquake-induced water level changes in the YuZ-5 well, Kamchatka, Vulkanol. Seismol., 2006, no. 6 , pp. 52-64.

Kopylova, G.N., The application of water level observations in wells for searching earthquakes precursors (on the example of Kamchatka), Geofiz. Issled., 2009, vol. 10, no. 2, pp. 56-68.

Kopylova, G.N. and Boldina, S.V., Estimation of poreelastic parameters for a reservoir of ground water (based on water level observations at YuZ-5 well, Kamchatka), Vulkanol. Seismol., 2006, no. 2, pp. 17-28.

Kopylova, G.N. and Boldina, S.V., The response of water level in the YuZ-5 well, Kamchatka to the magnitude 9.3, Sumatra-Andaman earthquake of December 26, 2004, J. Volcanol. Seismol., 2007, vol. 1, no. 5, pp. 319-327.

Kopylova, G.N. and Boldina, S.V., Hydrogeoseismological research in Kamchatka: 1977-2017, J. Volcanol. Seismol., 2019, vol. 13, no. 2, pp. 71-84.

Kopylova, G.N., Kulikov, G.V., and Timofeev, V.M., Assessment of the status and development prospects of hydrogeodeformational monitoring of seismically active regions of Russia, Razved. Okhr. Nedr, 2007, no. 11, pp. 75-83.

Kopylova G.N., Ivanov, V.Yu., and Kasimova V.A., The implementation of information system elements for interpreting integrated geophysical observations in Kamchatka, Russ. J. Earth Sci., 2009, vol. 11, no. 1, pp. 1-11.

https://doi.org/10.2205/2009ES000329

Kopylova, G.N., Boldina, S.V., Steblov, G.M., and Sdel'nikova, I.A., The possibility of estimating the coseismic deformation from water level observations in wells, $I z v$. Phys. Solid Earth, 2010, vol. 46, no. 1, pp. 47-56. https://doi.org/10.1134/S1069351310010040

Kopylova, G.N., Boldina, S.V., Smolina, N.N., Sizova, E.G., and Kasimova, V.A., Hydrogeoseismic variations in water level in the piezometric wells of Kamchatka (according to observations from 1987-2011), in Seismologicheskie $i$ geofizicheskie issledovaniya na Kamchatke: K 50-letiyu detal'nykh seismologicheskikh nablyudenii (Seismological and Geophysical Surveys in Kamchatka: On the 50th Anniversary of Detailed Seismological Observations), Gordeev, E.I. and Chebrov, V.N., Eds., Petropavlovsk-Kamchatskii: Novaya kniga, 2012, pp. 236-269.

Kopylova, G.N., Boldina, S.V., Smirnov, A.A., and Chubarova, E.G., An experience in registration of water level and physical and chemical parameters of ground waters in the wells due to strong earthquakes (on the example of Kamchatka), Seism. Prib., 2016, vol. 52, no. 4, pp. 43-56. https://doi.org/10.21455/si2016.4-4

Kopylova, G.N., Boldina, S.V., and Kasimova, V.A., The effects of strong earthquakes, $\mathrm{Mw}=6.8-9.1$, in changes in water level in the YuZ-5 well, Kamchatka, Trudy Shestoi nauchno-tekhnicheskoi konferentsii "Problemy kompleksnogo geofizicheskogo monitoringa Dal'nego Vostoka Rossii” (Proc. 6th Scientific and Technical Conference "Problems of Integrated Geophysical Monitoring of the Russian Far East"), Petropavlovsk-Kamchatskii, 2017, Obninsk: GS RAN, 2017, pp. 276-280.

Kopylova, G.N., Boldina, S.V., Smirnov, A.A., and Chubarova, E.G., Experience in registration of variations caused by strong earthquakes in the level and physicochemical parameters of ground waters in the piezometric wells: the case of Kamchatka, Seism. Instrum., 2017, vol. 53, no. 4, pp. 286-295.

https://doi.org/10.3103/S0747923917040065

Levina, V.I., Gusev, A.A., Pavlov, V.M., at al., Kronotsky earthquake on December 5, 1997 with $\mathrm{Mw}=7.8, \mathrm{I}_{0}=8$ (Kamchatka), in Zemletryaseniya Severnoi Evrazii v 1997 godu: Sbornik nauchnykh trudov (Earthquakes of Northern Eurasia in 1997: Collection of Papers), Obninsk: GS RAN, 2003, pp. 251-271.

Matsumoto, N. and Roeloffs, E.A., Hydrological response to earthquakes in the Haibara well, Central Japan: II. Possible mechanism inferred from time-varying hydraulic properties, Geophys. J. Int., 2003, vol. 155, pp 899-913.

Riznichenko, Yu.V., The size of the core of a crust earthquake and seismic moment, in Roeloffs, E.A., Persistent water level changes in a well near Parkfield, California, due to local and distant earthquakes, J. Geophys. Res., 1998, vol. 103, no. B1, pp. 869-889.

Shalev, E., Kurzon, I., Doan, M.-L., and Lyakhovsky, V., Sustained water-level changes caused by damage and compaction induced by teleseismic earthquakes, J. Geophys. Res.: Solid Earth, 2016b, vol. 121, pp. 4943-4954.

https://doi.org/10.1002/2016JB013068

Shalev, E., Kurzon, I., Doan, M.-L., and Lyakhovsky, V., Water-level oscillations caused by volumetric and deviatoric dynamic strains, Geophys. J. Int., 2016a, vol. 204, pp. 841-851. https://doi.org/10.1093/gji/ggv483

Shi, Zh., Wang, G., and Liu, C., Co-seismic groundwater level changes induced by the May 12, 2008 Wenchuan earthquake in the near field, Pure Appl. Geophys., 2013, vol. 170 , pp. $1773-1783$.

https://doi.org/10.1007/s00024-012-0606-1

Shi, Zh., Wang, G., Manga, M., and Wang, C.-Y. Mechanism of co-seismic water level change following four great earthquakes - insights from co-seismic responses throughout the Chinese mainland, Earth Planet. Sci. Lett., 2015, vol. 430 , pp. $66-74$.

https://doi.org/10.1016/j.epsl.2015.08.012

Studies in the physics of earthquakes: Sbornik statei (Studies in the Physics of Earthquakes: Collection of Papers), Moscow: Nauka, 1976, pp. 9-27.

Sun, X. and Liu, Y., Changes in groundwater level and temperature induced by distant earthquakes, Geosci. J., 2012, 
vol. 16 , no. 3 , pp. $327-337$.

https://doi.org/10.1007/s12303-012-0022-7

Sun, X., Wang, G., and Yang, X., Coseismic response of water level in Changping well, China, to the Mw 9.0 Tohoku earthquake, J. Hydrol., 2015, vol. 531, pp. 1028-1039.

https://doi.org/10.1016/j.jhydrol.2015.11.005

Theoretical Basis and Observation Techniques of Seismic Underground Fluids, The Monitoring and Forecasting Department of China Earthquake Administration, Beijing: Seismology Press, 2007, pp. 98-110.

Wakita, H., Water wells as possible indicators of tectonic strain, Science, 1975, vol. 189, pp. 553-555.

Wang, C.-Y. and Manga, M., Earthquakes and Water, Lecture Notes in Earth Sciences, vol. 114, Berlin: Springer, 2010.

https://doi.org/10.1007/978-3-642-00810-8
Wang, C., Cheng, L.H., Chin, C.V., and Yu, S.B., Coseismic hydrologic response of an alluvial fan to the 1999 ChiChi earthquake, Taiwan, Geology, 2001, vol. 29, no. 9, pp. 831-834.

Weingarten, M. and Ge, S., Insights into water level response to seismic waves: a 24-year high-fidelity record of global seismicity at Devils Hole, Geophys. Res. Lett., 2014, vol. 41, pp. 75-80.

Zhang, Sh., Shi, Zh., Wang, G., and Zhang, Zh., Quantitative assessment of the mechanisms of earthquake-induced groundwater-level change in the MP well, Three Gorges Area, Pure Appl. Geophys., 2018, vol. 175, no. 7, pp. 24752484.

https://doi.org/10.1007/s00024-017-1643-6

Translated by M. Nazarenko

SPELL: 1. OK 